DIW BERLIN

Discussion

Papers
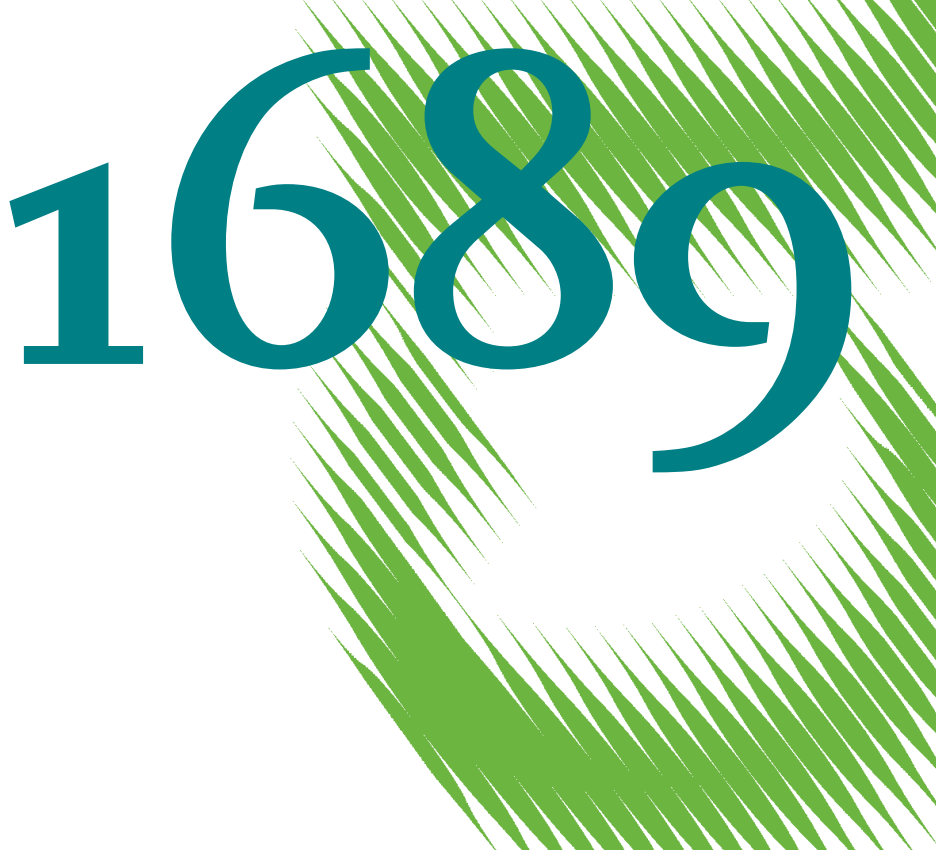

( 1

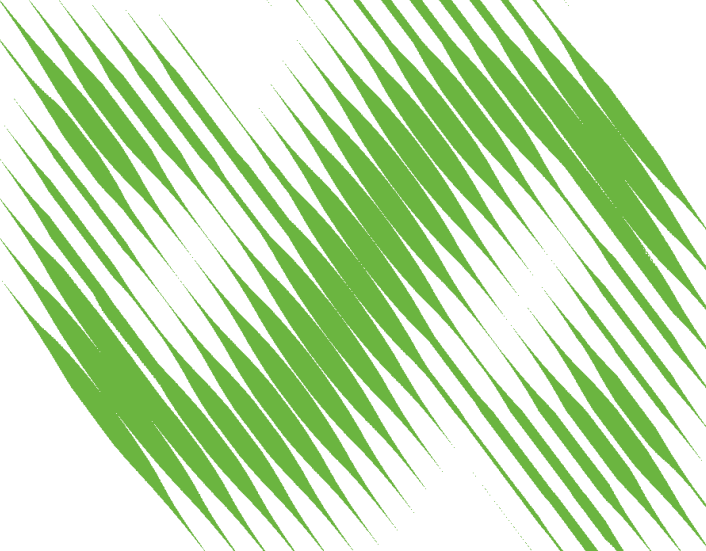

Does the EU ETS Cause Carbon Leakage in European Manufacturing? 
Opinions expressed in this paper are those of the author(s) and do not necessarily reflect views of the institute.

IMPRESSUM

(C) DIW Berlin, 2017

DIW Berlin

German Institute for Economic Research

Mohrenstr. 58

10117 Berlin

Tel. +49 (30) $89789-0$

Fax +49 (30) $89789-200$

http://www.diw.de

ISSN electronic edition 1619-4535

Papers can be downloaded free of charge from the DIW Berlin website:

http://www.diw.de/discussionpapers

Discussion Papers of DIW Berlin are indexed in RePEc and SSRN:

http://ideas.repec.org/s/diw/diwwpp.html

http://www.ssrn.com/link/DIW-Berlin-German-Inst-Econ-Res.html 


\title{
Does the EU ETS Cause Carbon Leakage in European Manufacturing?*
}

\author{
Helene Naegele, Aleksandar Zaklan ${ }^{\ddagger}$
}

September 25, 2017

\begin{abstract}
Carbon leakage is an issue of major interest in both academic and policy debates about the effectiveness of unilateral climate policy addressing global externalities. The debate is particularly salient in Europe, where the EU Emissions Trading System (EU ETS) covers emissions of many traded sectors. In a first step, we review how carbon leakage and the pollution haven effect are defined and identified in the literature. In a second step, we evaluate whether the emission cost introduced by the EU ETS has caused carbon leakage in European manufacturing. We compute trade flows in embodied carbon and value, using GTAP trade and input-output data and administrative data from the EU ETS. We evaluate the effect of four measures of environmental stringency on both net trade flows and bilateral trade flows. We do not find evidence that the EU ETS has caused carbon leakage.
\end{abstract}

JEL codes: F18, Q58, Q54

Keywords: Carbon leakage, pollution haven, EU ETS, cap-and-trade, $\mathrm{CO}_{2}$ emissions, policy evaluation.

\footnotetext{
${ }^{*}$ We thank conference participants in Zurich (EAERE), Lisbon (EARIE), Oviedo (EMEE) and Bergen (IAEE), and seminar participants in Toulouse and Berlin for fruitful discussions. We also thank Jan Abrell, Pio Baake, Sylvain Chabé-Ferret, Antoine Dechezleprêtre, Denny Ellerman, Christian von Hirschhausen, Philipp Richter, and Sebastian Schwenen for valuable comments. All remaining errors are ours.

${ }^{\dagger}$ DIW Berlin, Mohrenstrasse 58, 10117 Berlin, Germany. E-Mail: hnaegele@diw.de, Ph.:+49-30-89789518. Corresponding author.

${ }^{\ddagger}$ DIW Berlin, Mohrenstrasse 58, 10117 Berlin, Germany. E-Mail: azaklan@diw.de, Ph.:+49-30-89789-515.
} 


\section{Introduction}

Climate change caused by $\mathrm{CO}_{2}$ emissions is a global problem, but efforts to reduce $\mathrm{CO}_{2}$ emissions are mostly regional. In Europe and some states in the U.S., for example, policy initiatives exist, but no binding international agreement is in force. ${ }^{1}$ Unilateral, geographically limited policies increase production costs for domestic producers who compete internationally with producers from unregulated regions. This asymmetry raises the fear of carbon leakage - a shift of $\mathrm{CO}_{2}$ emissions from a region with emission constraints to an unconstrained area, via a change in relative competitiveness in an open global economy. Carbon leakage is a concern both in the academic debate and in policy circles (Ellerman et al. 2016). As climate change depends on aggregate global emissions, carbon leakage threatens to undo the effects of unilateral policy efforts. ${ }^{2}$ If carbon leakage occurs, the region implementing the policy suffers from a decrease in output and a consequent loss in employment and welfare, additionally to an ineffective environmental policy. The issue is particularly salient when manufacturing sectors are affected by an emissions policy, as they often produce goods that are both carbon intensive and heavily traded.

In this paper, we ask whether the EU ETS, the most important unilateral emissions policy to date, has caused carbon leakage in European manufacturing sectors. More specifically, we test if (parts of) the evolution of sectoral trade intensities can be explained by the stringency of environmental policy. Our empirical analysis in this paper does not provide any evidence of carbon leakage.

In theory, carbon leakage occurs between a domestic region featuring an emissions policy and a foreign region with no policy or a less stringent policy. It results from the combination of two effects: (i) relocation, when domestic firms shift their production to foreign countries to evade the increased production cost imposed by the environmental policy; and (ii) changes in market shares, when domestic firms lose market share to unregulated foreign competitors, who become more competitive as they do not have to bear the additional cost burden. ${ }^{3}$ Both effects translate directly into trade flows: for a given level of domestic consumption of a carbon-intensive product, carbon leakage leads to a higher share of imports in total consumption of the home region and to lower exports.

\footnotetext{
${ }^{1}$ The 2015 Paris agreement is neither binding nor does it involve symmetric compliance costs.

${ }^{2}$ Carbon leakage is a case of the pollution haven effect - which has hitherto mainly been considered in the context of local pollutants (Ederington et al. 2005, Levinson and Taylor 2008) - applied to the global pollutant carbon dioxide. The pollution haven hypothesis states that polluting industries relocate to where pollution is cheap. With local pollutants and a pollution haven effect, the pollution is at least being displaced, i.e. the region implementing an environmental policy benefits from less local pollution in exchange for a loss in industrial production. With a global pollutant, carbon leakage undoes either part or all of the policy's mitigation effect, depending on the rate of leakage.

${ }^{3}$ Additionally, carbon leakage can also occur through a drop in the price of emission intensive commodities, usually fossil fuels whose prices are formed globally, due to a fall in global demand for these commodities as a result of the domestic environmental policy. Lower global energy prices may lead to an increase in the demand for fuels in the foreign region, leading to increased energy use there and, thus, carbon leakage (Harstad 2012, Jensen et al. 2015). We do not address this energy price channel of carbon leakage in this paper. However, we believe that to date it is of minor relevance in the case of the EU, the focus of our empirical analysis, as neither its share in global energy demand nor the stringency of its emissions policy are significant enough to materially affect prices in global energy markets.
} 
In practice, the case for carbon leakage is not clear cut. First, the difference in emission cost between Europe and emerging economies has so far been moderate, in particular relative to differences in labor cost. Labor unit cost in Europe is about 10 to 30 times higher than in emerging countries (Schröder 2016). Even though the emission cost is typically zero in other parts of the world, our data show that the emission cost imposed by the EU ETS is below $0.65 \%$ of material cost for 95 percent of European manufacturing sectors. Thus, the additional cost introduced by European emissions policy is comparatively small. Second, firms relocating production to a foreign region must pay fixed relocation costs. Relocation also has opportunity costs in the home market, such as a weaker market position and less influence in bargaining with policy makers. Third, emissions policies often combine costs and subsidies. For example, European manufacturing firms received large amounts of free emissions allowances ("free allocation"), which may be sufficient to counter the leakage risk (EU 2014, Schmidt and Heitzig 2014). ${ }^{4}$ Our data reveal that most sectors received a net subsidy from emissions trading, once free allocation is taken into account. Fourth, the business literature predicts an inverse effect of environmental regulation (Porter hypothesis): the negative competitiveness effects of unilateral environmental policy may be offset by successful incentives to innovate in lower-carbon products, spurring a broader productivity increase for firms affected by environmental policies (Porter and Van der Linde 1995). Innovation may be incentivized through the emission price signal (Calel and Dechezleprêtre 2016) or by providing explicit R\&D subsidies in parallel (Acemoglu et al. 2012, Aghion et al. 2016).

Our empirical analysis is based on the argument that leakage can be measured through changes in trade flows, as they include both leakage channels: production relocation away from Europe and loss of European firms' market shares. We create a dataset of global trade flows, emission costs and control variables by combining data from the Global Trade Analysis Project (GTAP) with data from the EU's Transaction Log (EUTL), the administration's repository of data on emissions, allocations of allowances and transactions in the EU ETS. While GTAP is frequently used for research on computable general equilibrium models, it has recently also been used for empirical research on international trade (Caron et al. 2014). Brunnermeier and Levinson (2004) stress the importance of using panel data, as we do in this study, to account for unobserved heterogeneity of sectors and trading partners. We estimate the effect of four potential measures of the EU ETS's stringency on trade flows in European manufacturing. Our measures of policy stringency account for both direct and indirect emission costs. Indirect emission cost arises from electricity use: industrial consumers of electricity pay at least part of the costs of embodied emissions, as power producers pass through their emission cost to wholesale prices of electricity (Fabra and Reguant 2014, Hintermann 2016). We use two measures of trade: first, we compute $\mathrm{CO}_{2}$ emissions embodied in the traded goods, and second we use trade value in U.S. dol-

\footnotetext{
${ }^{4}$ Free allocation of emissions allowances based on historical emission levels is an expensive measure to counter carbon leakage: in Phase II of the EU ETS (2008-2012), each year the regulator distributed close to 2 billion tCO2e allowances for free, which at the average 2012 price of $10.42 € /$ tCO2e amounts to a yearly opportunity cost of $€ 20.84$ billion for free allocation compared to full auctioning.
} 
lars. Flows in embodied $\mathrm{CO}_{2}$ are computed from input-output tables and measure the emissions necessary to produce the traded goods. Trade flows in embodied $\mathrm{CO}_{2}$ emissions are often not available, but they capture carbon leakage better than trade flows in value. In our analysis we follow two approaches suggested by the literature: a traditional approach focusing on net imports (Ederington et al. 2005, Levinson and Taylor 2008) and an approach in the spirit of New trade theory where we evaluate bilateral (two-way) trade flows (Aichele and Felbermayr 2012, 2015).

We find no evidence for carbon leakage in European manufacturing sectors. This result contrasts with predictions from ex ante modeling exercises, but is largely in line with findings from existing empirical research on the carbon leakage hypothesis in the context of the EU ETS.

Given the policy relevance of the leakage issue, a sizable literature, mostly based on ex ante computable general equilibrium (CGE) models, has attempted to predict the extent of carbon leakage from existing policy initiatives and potential modifications (as reviewed by Branger and Quirion 2014, Carbone and Rivers 2017). These ex ante approaches predict strong carbon leakage with leakage rates between 10\% and 30\% (Carbone and Rivers 2017, IPCC 2007). ${ }^{5}$ However, the predictions of ex ante approaches depend on model assumptions, e.g. whether the model includes relocation costs, and the implementation details of the considered emissions policy. Demailly and Quirion (2006) show that introducing output-based allocation in the EU ETS would eliminate leakage, at the cost of decreasing the incentive for producers to abate emissions. Gerlagh and Kuik (2014) show that allowing for technology spill-overs may even lead to carbon leakage from foreign countries into the EU.

Empirical ex post evidence on carbon leakage is limited. Much of the existing empirical literature considers the pollution haven effect in the U.S., i.e. the effect of increasing the stringency of local pollution regulation on trade flows. These contributions typically test for a link between net trade flows and the stringency of pollution control measures, as captured by the Pollution Abatement Cost (PAC) using survey data of U.S. manufacturers. ${ }^{6}$ The evidence in this literature is mixed. Jaffe et al. (1995) review the early contributions, and conclude that there is little evidence that environmental policy has affected trade flows; like other authors, they point to the relatively small magnitudes of environmental expenditures as an explanation. Dechezleprêtre and Sato (2017) review the more recent literature and conclude that there is some evidence in favor of the pollution haven hypothesis, even if the cost burden is small. In particular, Ederington et al. (2005) and Levinson and Taylor (2008) regress U.S. net imports on PAC and find that environmental policy did impact U.S. trade flows. Aichele and Felbermayr (2015) find a carbon leakage effect of the Kyoto protocol. Based on a "gravity model for carbon" they find that the carbon content

\footnotetext{
${ }^{5}$ Carbon leakage is usually quantified as the ratio of foreign emission increase over domestic emission reduction. If all domestic emission reduction from environmental policy is shifted abroad, carbon leakage is said to be $100 \%$.

${ }^{6}$ As the PAC survey encompasses a wide mix of environmental policies, this literature cannot attribute effects to a specific policy measure.
} 
of sector-level bilateral trade was significantly impacted by a country's ratification of the Kyoto Protocol. However, it remains unclear through which channel the Kyoto protocol has induced this effect.

To our knowledge, the carbon leakage hypothesis in the EU ETS has so far not been comprehensively evaluated empirically. Some research addresses the relocation channel: Dechezleprêtre et al. (2014) use a survey of multinational firms and find no evidence that the EU ETS induced the relocation of emission-intensive processes within multinational firms. Other research addresses the investment channel: using firm-level data on foreign direct investment (FDI) by German multinational companies, Koch and Basse Mama (2016) find no evidence that the EU ETS has contributed to relocation through an increase in outbound FDI. Martin et al. (2014) conduct a survey of managers; they find that relocation risk is limited and that the current EU ETS rules largely over-compensate many sectors given the small risk of relocation. Finally, one strand of literature examines trade flows in specific sectors: Sartor (2013) finds that the EU ETS has not caused carbon leakage in the aluminum sector, while Branger et al. (2016) find no leakage in the cement and steel sector.

We contribute to the literature in several ways: first, we assess both the relocation and the competitiveness impact of the EU ETS by using global sector-level trade data. This approach complements studies focusing on relocation using firm-level data, e.g. Martin et al. (2014) or Dechezleprêtre et al. (2014). Second, using a broader dataset and focusing on a particular policy initiative whose cost can be captured explicitly, we complement previous work on carbon leakage effects of unilateral climate policy. Third, the inputoutput information in our data allows us to consider all embodied emissions in our outcome variable (trade flows) and our policy variable (emission policy), i.e. both direct and indirect emissions from electricity use.

In the following, we first review the relevant trade theory in Section 2 and then present our empirical implementation in Section 3. This is followed by a description of the data in Section 4 and presentation of results in Section 5. We summarize and conclude in Section 6 .

\section{Trade theory and carbon leakage}

\section{1. (Neo-)classical approach}

Classical and neo-classical models rely on Ricardo's theory of comparative advantage, formalized in the Heckscher-Ohlin-Vanek/Samuelson (HOV) model of international trade. In this view of the world, countries are characterized by their unequal endowment of relatively immobile production factors (land, labor), while sectors differ in their factorintensities and exhibit constant or decreasing returns to scale. A country has a comparative advantage and will specialize in those sectors that are intensive in its relatively abundant factor. Trade in goods essentially amounts to trading bundles of factor inputs, such that 


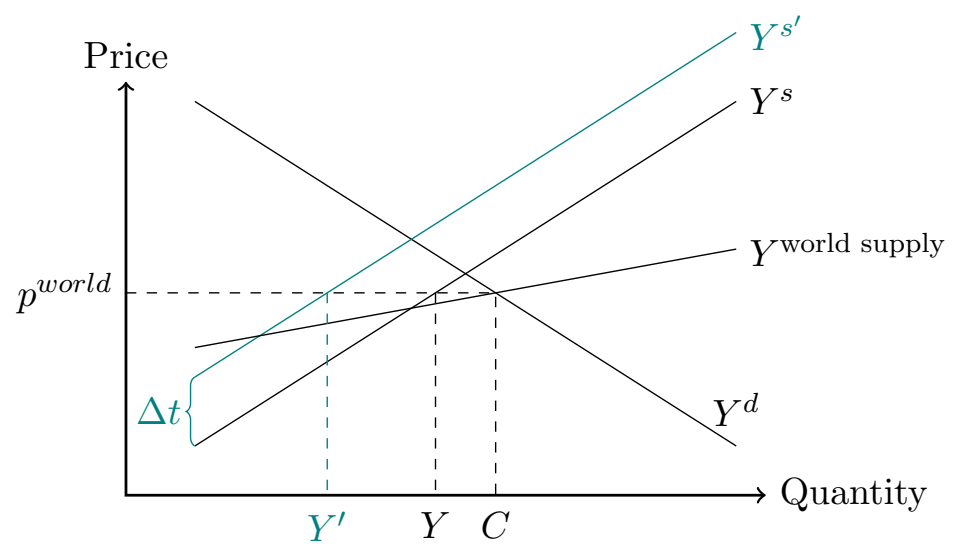

Figure 1: Stylized illustration of the pollution haven hypothesis

trade equalizes factor prices across countries.

Pethig (1976) establishes the link between a classical HOV model and the pollution haven hypothesis: emissions can be seen as a production factor, and countries with loose emission regulation are more abundant in this factor. ${ }^{7}$ This allows us to directly apply the findings of the general HOV model to the effect of an emissions policy: countries with high emission costs specialize in low-emission sectors and trade leads to equal pollution cost across countries in equilibrium (similar results can be found in Copeland and Taylor 2004, Motta and Thisse 1994, McGuire 1982). Antweiler et al. (2001) decompose the effect of trade liberalization on pollution into composition, scale and technique effects. Copeland and Taylor (2005) show in a three-region model, that the Kyoto protocol may either increase or decrease world pollution, depending on the model setup.

In order to better understand the concept of carbon leakage, it is useful to consider a stylized illustration of the pollution haven problem, assuming a one-sector economy. Figure 1 illustrates the case of a homogeneous good, immobile production factors and a large country in a neo-classical model. Without an environmental policy, the country produces $Y$ units and consumes $C$; the difference between $Y$ and $C$ is imported. When emissions become costly, e.g. through the introduction of an emissions tax $t$, the supply curve shifts upwards by $\Delta t$ and the new level of domestic production is $Y^{\prime}$. Consumption does not change, while imports increase. If production is equally emission-intensive everywhere in the world, then the total domestic emission reduction is entirely replaced by an increase in foreign emissions and the total effect for global emission mitigation is zero, i.e. carbon leakage is $100 \%^{8}$

In classical models, unilateral environmental policy unambiguously decreases quantities in the regulated country. However, the marginal effect on revenues (prices times quantities)

\footnotetext{
${ }^{7}$ Pethig (1976) assumes emissions enter through a Cobb-Douglas production function. While a CobbDouglas production function per se is a restrictive assumption, Levinson and Taylor (2008) show that this is equivalent to a situation where (a.) firms abate optimally given stringency of environmental policy and (b.) pollution abatement cost can be measured as a fraction of total factor use.

${ }^{8}$ In a more nuanced model, substitution between domestic and foreign products is not perfect, there exist trading costs, and technology is not fixed.
} 
is not always determined: McGuire (1982) shows that environmental policy drives the regulated country out of production of emission-intensive goods entirely, if factors are mobile (unambiguously reducing exports/increasing imports; similarly to Pethig 1976); whereas it merely breaks factor price equalization and changes world commodity prices, if factors are immobile. In the latter case, revenues decrease if the country is small, but revenues can increase or decrease (not determined) if the country is large. This is why we mainly rely on regressions using trade flows in emissions (quantities) and only add trade flows in values (revenues) for completeness. Measures of value are commonly used in the empirical trade literature, even though it is impossible to disentangle price and quantity effects (De Loecker et al. 2016).

(Neo-)classical models are criticized because they fail to explain that countries simultaneously import and export the same commodity with the same trading partner (called intra-industry trade or two-way trade), which empirically accounts for a sizable share of total trade flows. ${ }^{9}$ As a consequence, empirical work based on (neo-)classical trade models focuses on net trade flows, i.e. on the difference between imports and exports for each trading partner. We follow this approach in the first part of our empirical analysis.

\subsection{New trade approach}

More recently, the literature on trade theory has turned to New trade theory (Dixit and Stiglitz 1977, Krugman 1980), and "New" new trade theory focusing on heterogeneous firms (Melitz 2003). New trade models typically assume increasing returns to scale, providing a reason for specialization beyond initial factor endowments. Models typically assume a CES utility function, monopolistic competition and consider trade in intermediaries. Equilibrium flows of bilateral trade then depend on the market capacity of the importer and supply capacity of the exporter, as well as sectoral demand elasticities and trade costs. Dixit-Krugman-style models are used to derive a theoretical foundation for the gravity equation (Head and Mayer 2014). By assuming a "love of variety", New trade theory helps explaining the existence of intra-industry trade. A central result is that the representative consumer spreads consumption evenly over differentiated goods within a sector.

The (neo-)classical argument behind the pollution haven hypothesis can be seen as a competitiveness effect, arising from the full cost pass-through of firms in perfect competition. The impact of environmental regulation on trade flows in New trade approaches is more complex: on the supply side, the cost of emissions enters through higher input prices and reduces quantities and the equilibrium number of firms (and thus produced varieties) in the regulated region, therefore increasing imports and decreasing exports. On the demand side, the policy can impact the domestic price index, which makes the regulated region relatively poorer and dampens the increase in imports by reducing overall consumed quantities. In an application, Aichele and Felbermayr (2015) use a Dixit-Krugman-style

\footnotetext{
${ }^{9}$ Moreover, HOV models typically predict more trade than what is found empirically.
} 
model to analyze the impact of the ratification of the Kyoto Protocol on $\mathrm{CO}_{2}$ embodied ${ }^{10}$ in trade flows. ${ }^{11}$

Within a New trade model based on monopolistic competition, the effects of emissions policy both on quantity and on revenue are negative. ${ }^{12}$ Empirical applications of New trade models use bilateral trade data, i.e. imports and exports are separate observations. We pursue an analogous approach in the second part of our empirical analysis. Classical models typically feature neither horizontal nor vertical differentiation. New trade models account for horizontal but not vertical differentiation. Throughout this study, we assume that there is only horizontal differentiation within sectors.

\section{Empirical Implementation}

\subsection{Measures of environmental stringency}

Following Jaffe et al. (1995) and Brunel and Levinson (2016), we note that there are many possibly ways to measure environmental stringency. Depending on the policy implemented, compliance costs are the sum of costs of abating emissions and cost of remaining emissions. In the case of command-and-control policies, affected firms only pay abatement costs, whereas with a carbon pricing scheme they bear the costs of both abating emissions and paying for remaining emissions. The compliance cost of any policy can be offset through direct transfers to the affected firms.

Much of the empirical literature on the pollution haven effect in the U.S. uses data on the Pollution Abatement Cost (PAC) (e.g. Tobey 1990, Grossman and Krueger 1991, Ederington et al. 2005, Levinson and Taylor 2008). PAC is a summary measure of firms' expenditures on the abatement of local pollutants across a range of policies, based on survey data. ${ }^{13}$ Abatement cost is a reasonable measure for total compliance cost when studying command-and-control policies.

\footnotetext{
${ }^{10}$ Embodied $\mathrm{CO}_{2}$ is computed from input-output tables and measures the emissions necessary to produce the traded goods.

${ }^{11}$ However, New trade models tend to quickly get intractable. In order to apply the model empirically, Aichele and Felbermayr (2015) simplify by accounting only for trade between two regions, regulated and unregulated, and by dropping trade in intermediary goods.

${ }^{12} \mathrm{~A}$ simple example of a firm maximizing its profit $\pi$ shows that revenue (product of price and quantity) decreases with an increase in environmental regulation (i.e. a reduction in emissions $e$ ). With quantity $q(p)$ and cost function $c(q(p), e)$ both continuous and twice differentiable, and partial derivatives $q_{p}<0$, $c_{q}>0, c_{e}<0$ and $c_{q e}<0$, we have:
}

$$
\begin{aligned}
\pi & =p q(p)-c(q(p), e) \\
\text { firm's FOC } p^{*}(e) & : \frac{\partial \pi}{\partial p}=p q_{p}+q-c_{q} q_{p}=0 \\
\text { thus : } & \operatorname{sign} p_{e}^{*}=\operatorname{sign} c_{q e}<0 \\
\frac{\partial p^{*} q\left(p^{*}\right)}{\partial e} & =p_{e}^{*} q\left(p^{*}\right)+p^{*} q_{p}\left(p^{*}(e)\right) p_{e}^{*}=0 \\
& =\underbrace{p_{e}^{*}}_{<0} \underbrace{\left(q\left(p^{*}\right)+p^{*}(e) q_{p}\left(p^{*}\right)\right)}_{<0 \text { from FOC } p^{*}(e)}>0
\end{aligned}
$$

\footnotetext{
${ }^{13}$ PAC data have only been collected for the U.S. and the data series was discontinued after 2005 .
} 
We argue that emission costs are a more appropriate measure of environmental policy stringency when studying an emissions trading scheme; not only because the other element of total compliance cost, that is abatement cost, remains unobservable to the econometrician in the absence of a survey. The available literature finds that abatement in manufacturing sectors due to the EU ETS during the period covered by this paper was modest (Martin et al. 2016), so that the emission cost constitutes the main share of compliance cost. ${ }^{14}$ In practice, the emission cost imposed on sectors by the EU ETS is likely to be more precisely measured than PAC: it is based on administrative data reflecting the entire population of production plants regulated under the EU ETS, avoiding potential selection bias and response biases from a voluntary firm survey. Moreover, dealing with one policy only instead of a summary measure as in the case of PAC facilitates the attribution of causal effects.

We suggest several measures of the stringency of environmental policy: a binary treatment indicator $\theta^{1}$, and continuous measures of the components of emission cost (direct $\theta^{d}$, indirect $\theta^{i}$, and allocation $\theta^{a}$ ).

- $\theta_{i s t}^{1}=1$ if the sector's activity is explicitly regulated under the EU ETS, and 0 otherwise. ${ }^{15}$ The dummy variable $\theta_{i s t}^{1}=1$ indicates that producers in sector $s$ of country $i$ are required to participate in the EU ETS's compliance mechanism in year $t$. In addition to greater policy stringency, the binary indicator might capture transaction costs from being included in the scheme more broadly, such as annual verification of emissions and surrender of allowances.

- $\theta_{i s t}^{d}=P_{t}^{e} e_{i s t}$, where $P_{t}^{e}$ is the allowance price and $e_{i s t}$ are the sector's direct emissions covered by the EU ETS. $\theta_{i s t}^{d}$ captures the direct emission cost imposed by the EU ETS on sector $s .{ }^{16}$

- $\theta_{i s t}^{i}=P_{t}^{e} e l e c_{i s t}$, where $e l e c_{i s t}$ is the amount of emissions embodied in the sector's consumption of electricity, calculated from input-output data. $\theta_{i s t}^{i}$ captures the $i n$ direct emission cost, as allowance prices are passed through to prices of electricity, so that manufacturers ultimately pay for $\mathrm{CO}_{2}$ emitted in electricity production (Fabra and Reguant 2014, Hintermann 2016). ${ }^{17}$

- $\theta_{i s t}^{a}=P_{t}^{e} a_{i s t}$, where $a_{i s t}$ is the amount of allowances freely allocated to the sector $s$.

\footnotetext{
${ }^{14}$ Moreover, the abatement cost - if there is any abatement - should be highly correlated to emission stringency and, thus, emission costs, such that our measure is at least a good proxy for environmental stringency.

${ }^{15}$ The targeted sectors are: cement; chemicals, rubber, plastic prods; iron and steel; metal products; paper products; petroleum and coal products; other metals; other minerals (which includes glass and ceramics).

${ }^{16}$ In addition to the sector activities included explicitly, secondary activities are included in all sectors, usually in-house electricity generation through combustion installations. $\theta^{d}$ captures all these costs, while $\theta^{1}=0$ in many sectors.

${ }^{17}$ Fabra and Reguant (2014) and Hintermann (2016) find that power producers pass through their emission costs to electricity wholesale prices fully. In case pass-through is less than complete, our measure of indirect emission cost constitutes an upper bound.
} 
$\theta_{i s t}^{a}$ captures the lump-sum subsidy that is part of the EU ETS; it is not a cost, but a benefit.

- $\theta_{i s t}^{t o t}=\theta_{i s t}^{d}+\theta_{i s t}^{i}-\theta_{i s t}^{a}$, the total net cost of the EU ETS.

Following a suggestion by Ederington et al. (2005), we normalize these emission cost measures by the sector-level material cost, ${ }^{18}$ to account for environmental stringency while eliminating absolute magnitude effects (cf. Appendix A).

\subsection{Identification}

When regressing trade flows on environmental stringency, it is important to consider endogeneity concerns and potential omitted variable bias. We also discuss in this section what assumptions are necessary about unobserved foreign emission costs.

We control for unobserved sector heterogeneity by including industry-country and time fixed effects. In the following, we go through the elements of our definition of environmental stringency: the dummy, the emission levels, the allowance price, and the allocation, in order to consider whether remaining variation causes endogeneity of $\theta$.

First, the binary treatment indicator $\theta^{1}$ indicates that the EU explicitly targets a sector for its primary activity. Did the regulator select sectors for inclusion under the EU ETS based on their leakage risk or trade intensity? Our data indicate that the covered sectors are those with the largest historical emissions, which are determined by their production technology, not by their leakage risk.

Second, a similar argument applies to sectoral emission intensities as included in the continuous stringency measures. Emission levels depend on produced quantities, but we normalize by material cost to obtain emission intensities. We assume that emission intensity results from sector-specific technology, which is fixed in the short term and independent of import intensity. If we did not normalize by dividing through material cost, the common correlation of imports, exports and emissions with produced quantities would lead to spurious correlation. In Appendix A, we verify that we do not induce a bias by using normalized variables.

Third, allowance prices cannot depend on trade flows at the sector level. This is unlikely to be the case, as none of the manufacturing sectors had emissions large enough to substantially influence the price of $\mathrm{CO}_{2}$ allowances. In fact, the majority of demand for $\mathrm{CO}_{2}$ allowances comes from the electricity sector, with over $60 \%$ of total emissions in the EUTL in Phase II. ${ }^{19}$

Fourth, the definition of $\theta_{i s t}^{a}$ and of $\theta_{i s t}^{t o t}$ includes free allocation of emission allowances, which the regulator has explicitly introduced to mitigate the risk of carbon leakage. However, the EU distributed free allocations to all sectors in our sample, as they were all

\footnotetext{
${ }^{18}$ Alternatively, one could normalize by output, but the correlation between output and material cost is close to one, so that this choice is not relevant in practice.

${ }^{19}$ The electricity sector is not included in our analysis directly, as electricity is not traded globally.
} 
deemed to be at risk of carbon leakage. The level of free allocation is proportional to historical emissions (EU 2014), thus exogenous once we account for industry fixed effects.

Consequently, the risk of endogeneity seems limited. However, there may be omitted variables that drive both trade flows and environmental stringency (energy prices) or that modulate the strength of carbon leakage (transport costs).

Energy input prices are linked to both right-hand and left-hand variables of our regression. In one direction, causality seems excluded: energy prices are determined in the global market, and the impact of the EU ETS on global petrol, coal and gas prices is negligible. In the other direction, increasing energy prices will decrease both trade flows in $\mathrm{CO}_{2}$-intensive goods, as the rising input costs make them more expensive, and $\mathrm{CO}_{2}$ allowance prices, as with declining production producers of $\mathrm{CO}_{2}$-intensive goods demand fewer allowances. This may bias our estimate of carbon leakage upwards. As the central result of our paper is that we do not find any significant carbon leakage effect, this actually strengthens our conclusions.

Trade costs, in particular tariffs and transportation costs, affect how easily a product is traded and, in equilibrium, influence the "home bias." Consequently, sectors with high transport costs are naturally sheltered from foreign competition, reducing the risk of carbon leakage. An identification problem arises if, as argued by Ederington et al. (2005), there is a positive correlation between transport costs and carbon intensity. If transport costs are particularly high for emission-intensive sectors that also have high emission cost, this would bias our estimate towards zero. To control for this effect, we explicitly include transport cost in all our regressions and perform a robustness test using the interaction of our measures of environmental stringency and transport costs (cf. Section 5.1.2).

Finally, we do not include data on emission policies other than the EU ETS. Therefore, our estimates relate the change in European emission policy to changes in trade flows, taking all other emission policy as given. To our knowledge, the only major emission policy during the period 2004-2011 is the Kyoto Protocol: Kyoto signatory countries pledged to reduce emissions or otherwise purchase Kyoto allowances at the country level. However, producers from Kyoto signatory countries outside the EU did not face emission costs at the sector level. ${ }^{20}$ In some regions, emissions control policies similar to the EU ETS were introduced after 2011, the final year in our sample, e.g. in California, Quebec and at the provincial level in China.

\subsection{Net flows}

Following the literature, we examine the data from two angles. First, we consider net trade flows as in the classical approach, i.e. the difference of imports and exports at sectorcountry-year level (this subsection). Then, we analyze bilateral trade flows, including (two-way) intra-industry trade, at the sector-source-destination-year level in the spirit of

\footnotetext{
${ }^{20}$ These country-level emission reductions were easily achieved in most cases, either because of generous targets, e.g. in Russia, or due to emission reductions caused by lower production during the economic crisis that started at the end of the last decade.
} 
New trade theory (Subsection 3.4).

In the vein of Ederington et al. (2005), we estimate the following equation on net trade flows:

$$
y_{x s t}=\alpha \theta_{s t}+\beta \tau_{s t}+\gamma F_{s t}+\delta t_{s t}+\nu_{t}+\nu_{x s}+\epsilon_{x s t}
$$

where $y_{x s t}$ are the net imports - in value or in embodied carbon - of the EU from sector $s$ and country $x$ in year $t . \theta_{s t}$ is either the ETS dummy variable $\theta_{s t}^{1}$, the total net ETS cost $\theta_{i s t}^{t o t}$, or the vector of emission cost components $\left[\theta_{s t}^{d}, \theta_{s t}^{i}, \theta_{s t}^{a}\right] . \tau_{s t}$ is the EU's average import tariff for goods from sector $s . \nu_{t}$ are year fixed effects, $\nu_{x s}$ are sector-source country fixed effects. $F_{s t}$ is a vector of sector-level factor payments to unskilled labor, skilled labor and capital in percentage of total value added; the factor payment to skilled labor is omitted as the three add up to $1 .^{21} t_{s t}$ are transportation costs between source and destination countries, normalized by the free-on-board (FOB) value of trade flows. $\epsilon_{x s t}$ is an error term. Following another suggestion by Ederington et al. (2005), we normalize trade flows by a sector's total output, in order to compare outcomes of similar magnitude.

In classical theory, the effect of emission policy on for net imports $y_{x s t}$ in embodied carbon is unambiguous, but it not always clear for net imports in value. If the EU ETS caused carbon leakage, the coefficient of environmental policy stringency $\theta_{s t}$ is positive: more stringent policies, i.e. a higher emission cost, decrease carbon exports and/or increase carbon imports, which both translate into higher net imports of embodied carbon.

Year fixed effects control for general business cycles that are not sector-specific and sector-country fixed effects control for partner country size, sectoral specialization and distance to the EU. Our parameter of interest $\alpha$ is identified from the correlation of environmental stringency to within sector-country changes beyond the overall business cycle (difference-in-differences). The hypothesis is that increases in net imports should correlate with the stringency of environmental policy; in particular, for some sectors environmental stringency is negligible, so that there is no reason for carbon leakage in these sectors. ${ }^{22}$

\subsection{Bilateral flows}

Relying on a New trade model, Aichele and Felbermayr (2015) use bilateral flow data in traded value and in embodied $\mathrm{CO}_{2}$ emissions to test for carbon leakage. In this spirit, we estimate the following equation:

\footnotetext{
${ }^{21}$ Value added is distributed to unskilled labor, skilled labor and capital. We include factor payments in order to replicate the methodology in Ederington et al. (2005): they argue that including factor payments is not a valid test of the HOV model, but that they are still valid industry control variables. For robustness, we include the same regression without factor payments in the Appendix B.1.

${ }^{22}$ Indeed, no sector is completely protected from emission costs, as all sectors use at least some electricity. However, sectors like electronic equipment or wearing apparel have measured environmental stringency close to zero (total cost impacts of less than $0.04 \%$ of material cost). Our method only identifies sectorspecific variation, i.e. if there is a leakage component common to all sectors, it will be filtered out by our fixed effects.
} 


$$
y_{x m s t}=\alpha^{m} \theta_{m s t}+\alpha^{x} \theta_{x s t}+\beta \tau_{m s t}+\gamma F_{m s t}+\delta t_{m s t}+\nu_{m t}+\nu_{x t}+\nu_{s t}+\nu_{m x s}+\epsilon_{m x s t}
$$

where $y_{m x s t}$ is the trade flow - in value or in embodied carbon - from country $x$ to country $m$ in sector $s$ and year $t . \theta_{m s t}$ is either the ETS dummy variable $\theta_{m s t}^{1}$, the total net ETS cost $\theta_{i s t}^{t o t}$, or the vector of emission cost components $\left[\theta_{m s t}^{d}, \theta_{m s t}^{i}, \theta_{m s t}^{a}\right]$, of the importer $m$, and $\theta_{x s t}$ is the analogously defined variable for the exporter $x . \tau_{m s t}$ is the destination country's average import tariff for goods of sector $s . \nu_{m t}$ and $\nu_{x t}$ are countryyear fixed effects capturing business cycles at the national level. $\nu_{s t}$ are sector-year fixed effects capturing global shocks at the sector level. $\nu_{m x s}$ are sector-country pair fixed effects capturing sector-specific differences in trade intensity between two trading partners. ${ }^{23} t_{m s t}$ are transportation costs between source and destination countries, normalized by the FOB value of trade flows. $\epsilon_{m x s t}$ is an error term.

If the EU ETS caused carbon leakage, the effect of emission policy stringency $\theta_{m s t}$ (importer) on $y_{x m s t}$ is positive and/or the effect of $\theta_{x s t}$ (exporter) is negative: if a sector underlies more stringent environmental policy and suffers from leakage, then its exports decrease and imports increase. In New trade theory, the effect is unambiguous both for trade flows $y_{x m s t}$ in value and in embodied carbon.

Note that Aichele and Felbermayr (2015) define their treatment variable as the difference between ratification status with respect to Kyoto in the importing and in the exporting country: $\theta_{m x s t}^{1}=\left(\theta_{m s t}^{1}-\theta_{x s t}^{1}\right)$. This is equivalent to constraining the parameters in equation (2) such that $\alpha^{m}=-\alpha^{x}$. In addition to the model of equation (2), we also include this specification.

The sectoral business cycle is captured by the sector-year fixed effects. ${ }^{24}$ As typical in gravity-type estimations, the country-year fixed effects account for country size in the sense of supply capacity and market size that might fluctuate beyond global business cycles. Destination-source-sector fixed effects finally capture national specializations, institutional trade proximity and distance between both countries, i.e. factors that are pair-specific but do not fluctuate. Our parameters of interest $\alpha^{m}$ and $\alpha^{x}$ are then identified from the within sector-country-pair changes in trade flows beyond general trends and their correlation with changes in environmental stringency.

\footnotetext{
${ }^{23}$ We do not include factor payments in the main regression, as this does not fit with New trade models. For robustness, we include the same regression with factor payments in the Appendix B.2; this leads us to the same conclusions as our main specification.

${ }^{24}$ Note that for each sector-year, we have over 4,000 observations of which around 1,500 are trade flows coming from EU countries.
} 


\section{Data and descriptives}

\subsection{Data}

We use two main sources of data, the Global Trade Analysis Project (GTAP) version 9.2, ${ }^{25}$ and the EU Transaction Log (EUTL). ${ }^{26}$ We draw data on trade flows, $\mathrm{CO}_{2}$ emissions, factor payments, transport costs, output, and material costs for the years 2004, 2007, and 2011 from the GTAP database. The EU ETS was introduced in 2005, so that we have one period prior to the policy introduction and two periods after. GTAP 9.2 data are divided into 57 sectors and 140 countries. We aggregate smaller economies into regions, resulting in a dataset of 66 regions. We only keep the manufacturing sectors (25 out of 57 sectors), which are at the heart of the carbon leakage debate.

The major benefit of GTAP is that it offers consistent data at the global level and includes input-output (I-O) information. This allows us to fully account for emissions from both electricity and fossil fuel inputs. ${ }^{27}$ The I-O data also allow us to compute emissions embodied in the electricity consumed by each sector, i.e. indirect emissions and their cost.

We use data from the EU Transaction Log (EUTL) to compute our measures of policy stringency. The EUTL is an administrative dataset containing official yearly compliance data for all production plants regulated under the EU ETS, starting in 2005. We extract data on emissions and allocations from the EUTL and map them to the 4-digit NACE 2 code using an plant-to-NACE matching provided by the European Commission and compiled as part of the Ownership Links and Enhanced EUTL Project. ${ }^{28}$ We combine the EUTL data with GTAP data via the International Standard Industrial Classification (ISIC, a UN nomenclature); for this, we match the GTAP classification to ISIC following Huff et al. (2000) and the NACE level EUTL data to ISIC using correspondence tables from Eurostat. ${ }^{29}$ Finally, we add allowance prices for EU ETS emission allowances (EUAs) from the European Energy Exchange (EEX).

\subsection{Descriptive statistics}

In 2004, the year before the EU ETS was introduced, no firms based in Europe were liable for $\mathrm{CO}_{2}$ emissions, so the cost of embodied carbon was zero for all sectors. $\theta^{1}$ indicates that $32 \%$ of the EU's manufacturing sectors ( 8 out of 25 ) were directly targeted by the EU ETS (Table 1).

Carbon leakage is a medium to long-term phenomenon, so we choose average allowance

\footnotetext{
${ }^{25}$ See https://www.gtap.agecon.purdue.edu/databases/v9/ and Aguiar et al. (2016) for further details. ${ }^{26}$ http://ec.europa.eu/environment/ets

${ }^{27}$ Our aim is to capture total emissions, both from fossil fuels and process emissions. As the GTAP data only contain information on emissions from the use of fossil fuels, we correct for process emissions in sectors featuring a significant share of process emissions, i.e. iron and steel, cement and chemicals, using data from the UNFCCC (http://unfccc.int).

${ }^{28}$ http://fsr.eui.eu/climate/ownership-links-enhanced-eutl-dataset-project/

${ }^{29} \mathrm{http}$ ://ec.europa.eu/eurostat/ramon/index.cfm
} 
Table 1: Descriptive statistics

\begin{tabular}{|c|c|c|c|c|c|c|}
\hline & Mean & Median & SD & Min & $\operatorname{Max}$ & $\mathrm{N}$ \\
\hline \multicolumn{7}{|c|}{ Measures of environmental stringency (2007\&2011, only EU countries) } \\
\hline ETS dummy $\theta_{i s t}^{1}$ & $31.9 \%$ & 0 & $46.6 \%$ & 0 & 1 & 1,247 \\
\hline Direct ETS cost $\theta_{i s t}^{d}$ & $0.17 \%$ & $0.00 \%$ & $0.629 \%$ & 0 & $6.65 \%$ & 1,247 \\
\hline Indirect ETS cost $\theta_{i s t}^{i}$ & $0.16 \%$ & $0.07 \%$ & $0.332 \%$ & 0 & $4.37 \%$ & 1,247 \\
\hline Allocation benefit $\theta_{i s t}^{a}$ & $0.22 \%$ & $0.00 \%$ & $0.845 \%$ & 0 & $10.06 \%$ & 1,247 \\
\hline Total net ETS cost $\theta_{i s t}^{\text {tot }}$ & $0.11 \%$ & $0.05 \%$ & $0.442 \%$ & 0 & $6.81 \%$ & 1,247 \\
\hline \multicolumn{7}{|l|}{ EU net import flows } \\
\hline Net imports (Mil. US\$) & -146.4 & -38.0 & 3912.9 & -36892 & 84150.2 & 3,075 \\
\hline Net $\mathrm{CO}_{2}$ imports $(\mathrm{Mt})$ & 0.3 & 0.0 & 1.5 & -4.7 & 27.0 & 3,075 \\
\hline Net imp./output & $0.14 \%$ & $-0.02 \%$ & $1.5 \%$ & $-8.2 \%$ & $33.7 \%$ & 3,075 \\
\hline Net $\mathrm{CO}_{2} /$ total emiss. & $1.10 \%$ & $0.00 \%$ & $6.6 \%$ & $-7.0 \%$ & $161.9 \%$ & 3,075 \\
\hline Transport cost/FOB & $5.54 \%$ & $4.35 \%$ & $7.1 \%$ & $0.0 \%$ & $95.8 \%$ & 3,075 \\
\hline \multicolumn{7}{|l|}{ Bilateral flows } \\
\hline \multicolumn{7}{|l|}{ Outcomes } \\
\hline Trade flow (Mil. US\$) & 97.56 & 1.09 & 882.00 & 0 & 132123.3 & 321,360 \\
\hline $\mathrm{CO}_{2}$ flow $(\mathrm{Mt})$ & 0.02 & 0.00 & 0.22 & 0 & 21.65 & 321,360 \\
\hline Trade flow/output & $0.55 \%$ & $0.03 \%$ & $4.14 \%$ & 0 & $936.33 \%$ & 321,360 \\
\hline $\mathrm{CO}_{2}$ flow/total emiss. & $0.56 \%$ & $0.03 \%$ & $4.23 \%$ & 0 & $959.31 \%$ & 321,360 \\
\hline Carbon intensity & $0.04 \%$ & $0.01 \%$ & $0.14 \%$ & 0 & $4.46 \%$ & 320,035 \\
\hline \multicolumn{7}{|l|}{ Covariates } \\
\hline Zero tariffs & $46.9 \%$ & & $49.9 \%$ & 0 & 1 & 321,360 \\
\hline Tariff (if not zero) & $10.5 \%$ & $5.4 \%$ & $28.1 \%$ & 0 & $2475.9 \%$ & 170,689 \\
\hline$F_{\text {unskilled }} /$ value added & $19.5 \%$ & $17.1 \%$ & $11.4 \%$ & 0 & $68.6 \%$ & 321,360 \\
\hline$F_{\text {skilled }} /$ value added & $24.4 \%$ & $22.3 \%$ & $14.2 \%$ & 0 & $100.0 \%$ & 321,360 \\
\hline$F_{\text {capital }} /$ value added & $56.1 \%$ & $56.9 \%$ & $19.5 \%$ & 0 & $98.97 \%$ & 321,360 \\
\hline Transport cost/FOB & $4.7 \%$ & $3.2 \%$ & $6.5 \%$ & 0 & $147.2 \%$ & 320,035 \\
\hline
\end{tabular}

Note: Measures of environmental stringency are computed for 2007 and 2011, and show the emission cost as a share of sectoral material cost. $\theta^{1}$ is 1 for sectors explicitly targeted under the EU ETS, while $\theta^{d}$ also contains the direct emission costs of secondary activities. Additionally, $\theta^{i}$ captures indirect emission costs from the use of electricity. Carbon intensity is the ratio of a trade flow's embodied carbon over its value. We drop the observations from the Slovenian refinery sector which is an unrealistic outlier with over $22 \%$ of ETS cost. The number of observations is explained as follows: $1,147=2$ years ${ }^{*} 25$ sectors ${ }^{*} 25$ countries (- Slovenia refinery); $3,075=3$ years ${ }^{*} 25$ sectors $* 41$ partner regions; $321,360=3$ years* 25 sectors*66 source regions*(66-1) destination regions (- Slovenia refinery); some observations are dropped for carbon intensity and trade costs, as they have zero trade flows. 
prices over the EU ETS compliance Phase I (2005-2007) to compute $\theta^{d}, \theta^{i}$ and $\theta^{a}$ in 2007, and the average price for Phase II up to 2011 (2008-2011) for 2011. This leads to allowance prices of $€ 10.45$ per metric ton of $\mathrm{CO}_{2}$ in 2007 and $€ 14.53$ in $2011 .{ }^{30}$

The level of direct emission cost $\theta^{d}$ has an average of $0.17 \%$ and is below $1 \%$ of material cost for the large majority of sectors. Only the iron \& steel, cement, petroleum \& coal products, non-ferrous metals (incl. aluminum) and other minerals (incl. glass and ceramics) sectors exceed this threshold. ${ }^{31}$ Free allocation $\theta^{a}$ is on average $0.22 \%$, with allocations up to $10 \%$ of material costs; the resulting net direct ETS $\operatorname{cost}\left(\theta^{d}-\theta^{a}\right)$ is a net subsidy for the large majority of sectors. In general, allocations over-compensate direct emission cost, as evidenced by the slope of more than 1 between $\theta^{d}$ and $\theta^{a}$ (Figure 2, left-hand panel).

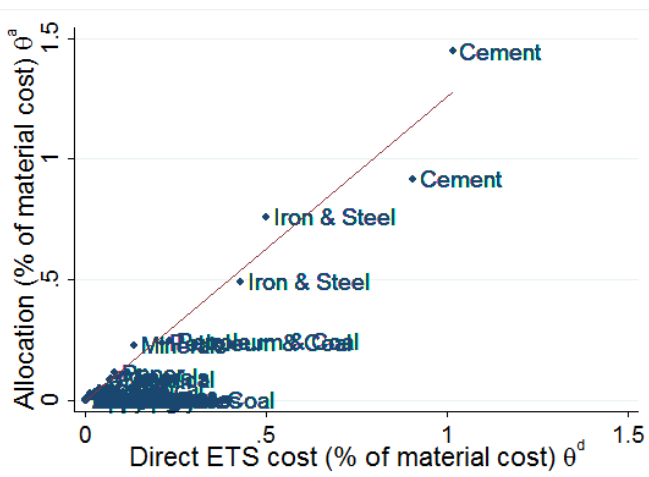

(a) Direct emission cost $\theta^{d}$ as a function of allocation $\theta^{a}$

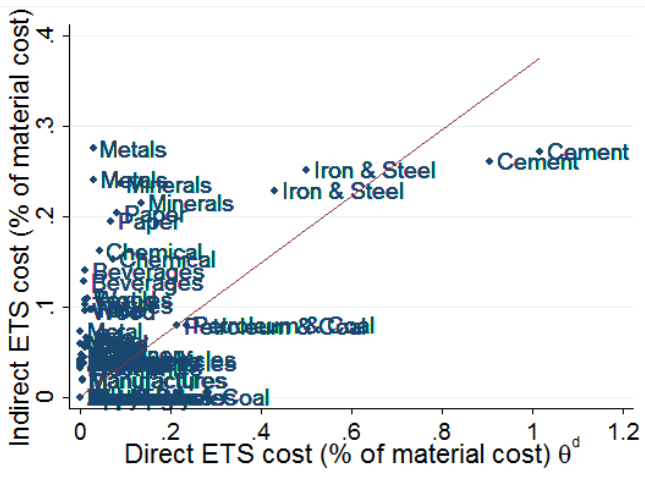

(b) Direct emission $\operatorname{cost} \theta^{d}$ as a function of indirect emission cost $\theta^{i}$

Figure 2: Correlation of the measures of environmental stringency (scatter and fitted linear trend, sector-year averages across countries, 2007 \& 2011)

Sectors also incur indirect ETS costs $\theta^{i}$ from their electricity use. Indirect emission costs account on average for $0.16 \%$ of material costs. The largest indirect emission costs occur in the non-ferrous metals and iron \& steel sectors, with up to $4.4 \%$ of material costs. For most sectors, indirect emission costs from electricity use are higher than direct costs, except for some emission-intensive sectors like cement and iron \& steel (Figure 2, right-hand panel). Adding up direct cost, indirect cost and subtracting the value of free allocation, EU manufacturing sectors were facing a net total emission cost of $0.11 \%$ of material cost on average over 2007 and 2011.

Our outcome variables are net trade flows and bilateral trade flows. We measure trade flows in value (U.S. dollars) and in embodied carbon, that is the sum of $\mathrm{CO}_{2}$ emissions from all combustibles that served as an input to the traded goods (including emissions from electricity generation). In order to account for size effects, we scale net imports with output value and net $\mathrm{CO}_{2}$ imports with total sectoral carbon emissions. The highest net imports both in value and as a share of output are electronic equipment from China. The

\footnotetext{
${ }^{30}$ Our results are robust to using prices from each year only, instead of multi-year averages.

${ }^{31}$ We excluded the petroleum and coal products sector in Slovenia, which is an outlier with a value of $22.5 \%$ of material costs in 2007. Our results are robust to using the full dataset, and to excluding observations at the largest and smallest percentile.
} 
highest embodied carbon net imports are in cement, also from China. Overall, Europe is a net importer embodied emissions via manufactured goods.
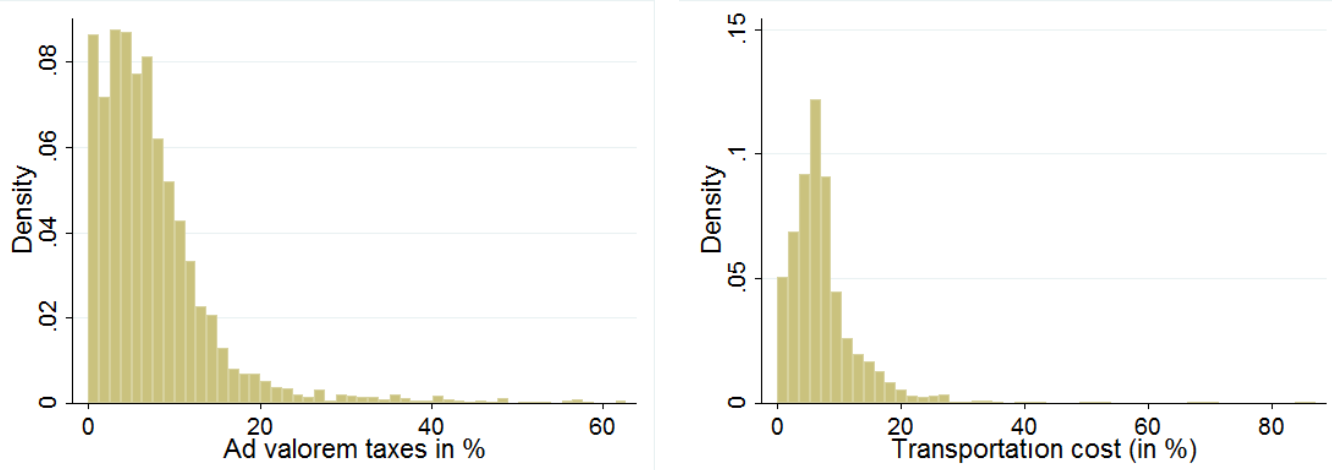

Figure 3: Distribution of import taxes and transport costs (sector-averages 2004-2011)

Other important determinants of trade flows are import tariffs and transport costs, which may blur the relationship between emission costs and trade flows. Almost half of all trade flows are not subject to import tariffs. Figure 3 (left-hand panel) shows the average tariffs of the remaining sectors that were $10.5 \%$ on average, ranging from almost zero to $62 \%$ (for the beverage and tobacco industry). Transport costs on bilateral trade flows amount on average to $4.7 \%$ of the FOB value of trade flows. Figure 3 (right-hand panel) shows that sector averages vary between almost zero and $84 \%$. The sectors with the highest transport costs relative to value are minerals and cement.
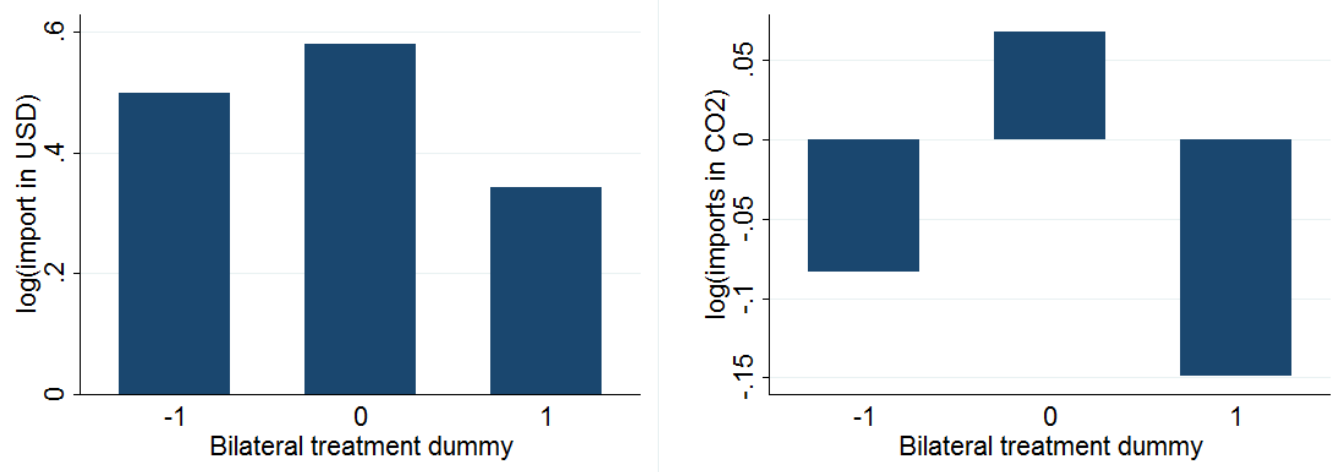

Figure 4: Imports in value and imports in embodied carbon by bilateral EU ETS treatment status

Average difference between pre- and post-treatment country pair-sector averages of the logarithm. 1 are trade flows from an untreated source country to a treated destination country; -1 are trade flows from a treated source to an untreated destination; 0 are trade flows between countries with same treatment status and within untreated sectors.

Figure 4 provides some descriptive evidence on the impact of the EU ETS on bilateral trade flows, similar to a Figure in Aichele and Felbermayr (2015), albeit applied to the EU ETS instead of the Kyoto protocol. We define a bilateral treatment variable as $\theta_{m x s t}^{1}=$ $\left(\theta_{m s t}^{1}-\theta_{x s t}^{1}\right) \in\{-1,0,1\}$. $\theta_{m x s t}^{1}$ is equal to 1 if the trade flow goes from an untreated source country $x$ to a treated destination country $m$ (within a treated sector); -1 for trade 
flows from a treated source to an untreated destination (within a treated sector); 0 for trade flows between countries with same treatment status or for trade flows of untreated sectors.

Figure 4 shows that bilateral trade in value has increased for all values of $\theta_{m x s t}^{1}$, and the magnitudes broadly match those in Aichele and Felbermayr (2015). Trade in embodied carbon decreased both for trade to and from treated countries, while it increased in nontreated countries and sectors. Carbon leakage would translate into larger imports to and smaller imports from treated sectors, i.e. an increasing slope in both panels of Figure 4, which does not appear in our data. The shift in trade in embodied carbon found by Aichele and Felbermayr (2015) must have occurred either prior to the introduction of the EU ETS or among non-EU countries who ratified Kyoto. Overall, the descriptive evidence does not suggest that imports in embodied carbon were affected by the introduction of the EU ETS.

\section{Results}

\subsection{Net trade flows}

\subsubsection{Main results}

As a first step, we implement the method suggested by Ederington et al. $(2005)^{32}$ : using net trade data, we regress net imports in value and in embodied carbon on $\theta^{1}$, as well as on the vector $\left[\theta^{d}, \theta^{i}, \theta^{a}\right]$. In all regressions, we control for European import tariffs, transport costs (as a percentage of import value), and factor payment shares (as a percentage of value added), as well as for year and sector fixed effects.

The results in Table 2 show no evidence of carbon leakage. None of the coefficients from regressions of net imports in embodied carbon on emission costs are significant. The (not significant) coefficient on the ETS dummy in Table 2 column (1), and its $95 \%$ confidence interval of $[-.621, .327]$ are consistent with a maximum increase of 0.327 percentage points in net carbon imports in the treated sectors relative to untreated sectors. The confidence intervals in columns (2) to (4) are wider, but the magnitude of the estimates is still small given that the standard deviation of direct ETS cost is 0.6.

The only coefficients that are (weakly) significant appear in the regression of net imports in value on the individual components of emission cost from the ETS: column (7) of Table 2 shows that net imports increased with direct ETS cost and decreased with allocation. The net effect in column (8) is about zero and not significant. This effect would be compatible with the hypothesis that there the carbon leakage effect has been alleviated by free allocation. However, as we cannot find the same effect in trade flows in embodied carbon, we conclude that it must be an artifact of price fluctuations. Indeed, we will see

\footnotetext{
${ }^{32}$ Ederington et al. (2005) aggregate over all partner countries of the U.S., while we use one observation per year-sector-partner country. Results on aggregate data yield the same result and are available on request, but the sample size shrinks to $\mathrm{N}=75$.
} 
Table 2: Regression results for EU net imports (by partner country and sector)

\begin{tabular}{|c|c|c|c|c|c|c|c|c|}
\hline \multirow[b]{2}{*}{ Emission cost } & \multicolumn{4}{|c|}{ Net embodied $\mathrm{CO}_{2} /$ total $\mathrm{CO}_{2}$} & \multicolumn{4}{|c|}{ Net imports/output } \\
\hline & $(1)$ & $(2)$ & $(3)$ & $(4)$ & $\overline{(5)}$ & $(6)$ & (7) & $(8)$ \\
\hline \multirow[t]{2}{*}{ ETS dummy $\theta_{s t}^{1}$} & -0.147 & & & & 0.001 & & & \\
\hline & $(0.242)$ & & & & $(0.043)$ & & & \\
\hline \multirow[t]{2}{*}{ Direct ETS cost $\theta_{s t}^{d}$} & & -0.096 & 0.782 & & & 0.034 & $0.310^{*}$ & \\
\hline & & $(0.272)$ & $(0.657)$ & & & $(0.129)$ & $(0.129)$ & \\
\hline \multirow[t]{2}{*}{ Indirect ETS cost $\theta_{s t}^{i}$} & & & -1.987 & & & & 0.033 & \\
\hline & & & $(1.983)$ & & & & $(0.295)$ & \\
\hline \multirow[t]{2}{*}{ Allocation benefit $\theta_{s t}^{a}$} & & & -0.495 & & & & $-0.256^{*}$ & \\
\hline & & & $(0.576)$ & & & & $(0.117)$ & \\
\hline \multirow[t]{2}{*}{ Total net ETS cost $\theta_{s t}^{t o t}$} & & & & -0.791 & & & & 0.010 \\
\hline & & & & $(0.892)$ & & & & $(0.165)$ \\
\hline $\mathrm{R}^{2}$ & 0.89 & 0.89 & 0.89 & 0.89 & 0.92 & 0.92 & 0.92 & 0.92 \\
\hline Obs & & & & 3,075 & olumns) & & & \\
\hline
\end{tabular}

Notes: OLS regression of outcome on different definitions of ETS cost. Data is a sector-country-level panel for 2004, 2007, and 2011; all regressions include year and sector-country fixed effects and control for factor payment shares, tariffs, and transport costs. Robust standard errors clustered at the sector-partner country level in parentheses. ${ }^{* *},{ }^{* *}$, and ${ }^{*}$ denote statistical significance at the $1 \%, 5 \%$, and $10 \%$ level, respectively.

that the significance of this result survives in none of our robustness checks. This result underlines, in our view, the importance of using embodied carbon flows, or at least trade flows in quantities rather than in value when doing an analysis of carbon leakage.

As a robustness test, we replicate the methodology of Levinson and Taylor (2008) by doing the same regression individually for each important trading partner country of the EU. We do not find any significant impact for any country. ${ }^{33}$

As a further robustness test, we do the same regressions without controlling for factor payment shares (see Table 6 in the Appendix), which exposes the fragility of the previously discussed significance result of column (7) in Table 2. We provide a compact overview of all regressions, including robustness checks, in Table 6 in the Appendix, where we only display coefficients of emission cost and their standard errors for all main specifications and robustness tests.

Additionally, we confirm that that our results are not affected by our normalization of the outcome variables (Appendix A). Our results suggest Branger et al. (2016) were right to call the debate about carbon leakage "much ado about nothing."

\subsubsection{Sector heterogeneity}

Ederington et al. (2005) hypothesize that transport costs play an important role for carbon leakage, as some sectors are more footloose than others: if transport costs are high, industries are relatively more protected from foreign competition, such that environmental stringency has different effects for different industries. Our estimate may be biased if transport costs are correlated with environmental stringency: a typical example is the cement industry. In this case, both the measure of environmental stringency and its interaction

\footnotetext{
${ }^{33}$ Results are available on request.
} 
with transport costs should have a significant negative coefficient.

In our data, we observe a low, but significant, positive correlation (of 0.06) between our measure of direct emission cost $\theta^{d}$ and transport costs, as well as a low, but significant, negative correlation (of -0.05) between our total net cost measure $\left(\theta^{d}+\theta^{i}-\theta^{a}\right)$ and transport costs. As suggested by Ederington et al. (2005), we correct for this correlation by interacting our measures of policy stringency with transport costs. The results in Table 3 show no significant effect (and are mostly of a sign not compatible with the carbon leakage hypothesis). ${ }^{34}$ Thus, we conclude that we do not find evidence that sectors transport costs played a role in mitigating carbon leakage.

Table 3: Regressions of net import flows on environmental cost and its interaction with transport costs and higher order terms of emission cost

\begin{tabular}{|c|c|c|c|c|c|c|}
\hline \multirow[b]{2}{*}{ Emission cost } & \multicolumn{3}{|c|}{ Net embodied $\mathrm{CO}_{2} /$ total $\mathrm{CO}_{2}$} & \multicolumn{3}{|c|}{ Net imports/output } \\
\hline & $(1)$ & $(2)$ & $(3)$ & (4) & $(5)$ & (6) \\
\hline ETS dummy $\theta_{m s t}^{1}$ & $\begin{array}{l}-0.258 \\
(0.498)\end{array}$ & & & $\begin{array}{l}-0.028 \\
(0.065)\end{array}$ & & \\
\hline ETS dummy $\times$ & -0.002 & & & 0.004 & & \\
\hline Transport cost & $(0.024)$ & & & $(0.005)$ & & \\
\hline Total net ETS cost $\theta_{m s t}^{t o t}$ & & $\begin{array}{l}-0.634 \\
(1.396)\end{array}$ & $\begin{array}{l}-0.444 \\
(1.300)\end{array}$ & & $\begin{array}{c}0.034 \\
(0.176)\end{array}$ & $\begin{array}{c}0.206 \\
(0.191)\end{array}$ \\
\hline $\begin{array}{l}\text { Total net ETS cost } \times \\
\text { Transport cost }\end{array}$ & & $\begin{array}{l}-0.022 \\
(0.077)\end{array}$ & & & $\begin{array}{c}0.016 \\
(0.019)\end{array}$ & \\
\hline $\begin{array}{l}\text { Total net ETS cost } \\
\text { squared } \\
\text { Total net ETS cost } \\
\text { cubed }\end{array}$ & & & $\begin{array}{c}-12.612 \\
(15.791) \\
30.657 \\
(42.866) \\
\end{array}$ & & & $\begin{array}{l}1.466 \\
(2.452) \\
-4.851 \\
(6.122) \\
\end{array}$ \\
\hline $\mathrm{R}^{2}$ & 0.89 & 0.89 & 0.89 & 0.92 & 0.92 & 0.92 \\
\hline Obs & & & 3,075 & lumns) & & \\
\hline
\end{tabular}

Notes: OLS regression of outcome on different definitions of ETS cost. Data is a sector-level for aggregated and sector-country-level panel for "by country", each for 2004, 2007, and 2011; all regressions include year and sector-country fixed effects and control for factor payment shares, tariffs, and transport costs. Robust standard errors clustered at the sector-partner country level in parentheses. ***, **, and

* denote statistical significance at the $1 \%, 5 \%$, and $10 \%$ level, respectively.

Our main regression is a linear approximation of the effect of environmental policy on trade. For robustness, we also fit a cubic polynomial (including two higher order terms of $\theta$ ) to control for heterogeneous effects of the emission cost depending on its level. Table 3 shows that the higher order terms are never significant, so that we find no evidence of nonlinear effects.

\subsection{Bilateral trade flows}

Bilateral trade flow data provide a richer picture of international trade, accounting for (two-way) intra-industry trade. Our sample size increases dramatically to over 300,000

\footnotetext{
${ }^{34}$ Results on the vector of components of emission costs yield the same result, but are not represented here for compactness; results available on request.
} 
observations, between 66 source and destination countries for three years and 25 sectors. With these data, we implement the identification strategy of Aichele and Felbermayr (2015): they define a bilateral treatment variable that is the difference of treatment status of destination and source country $\theta_{m x s t}=\left(\theta_{m s t}-\theta_{x s t}\right) \in\{-1,0,1\}$. This restricts the coefficients on treatment to be of opposite sign and identical magnitude: $\alpha^{m}=-\alpha^{x}$. In a second step, we relax this restriction and use separate emission cost measures for source and destination country.

Our regression results are shown in Table 4. Odd-numbered columns contain specifications using bilateral definitions of our emission cost variables, while even-numbered columns present the results with separate emission cost measures for source and destination country. Carbon leakage is consistent with significant positive coefficients of destination emission cost, and significant negative coefficients of source emission cost, and, thus, a positive effect of the bilateral variables.

Columns (1) and (7) show the specifications corresponding to Aichele and Felbermayr (2015), and both are not significant. Our confidence interval in column (1) is compatible with a maximum increase in carbon imports of $0.037 \%$; and column (7) allows for a maximum increase in imports in value of $0.376 \%$. In contrast, Aichele and Felbermayr (2015) find that Kyoto ratification increases imports by $5 \%$ and raises the carbon content of trade (what we call "trade in embodied carbon") by almost $8 \%$. We conclude that the carbon leakage found by Aichele and Felbermayr (2015) has occurred outside the EU or before the introduction of the EU ETS.

Again, the regressions of embodied carbon are not significant except for the coefficients of indirect emission cost in column (4). However, these coefficients are both positive: both carbon imports and exports increased with indirect emission cost. ${ }^{35}$ This is cannot be interpreted as carbon leakage; it thus must capture some other mechanism making electricity-intensive sectors in the EU more trade-intensive in both directions.

For trade flows in value, we have some coefficients that are significantly different from zero, but it is again not consistent with a carbon leakage explanation. The coefficient on the ETS dummy in column (8) has the "wrong" sign for the carbon leakage hypothesis. The signs of the coefficients in columns (9) and (10) have the "right" sign, but are not significant.

Table 7 in the Appendix provides additional results using bilateral variable definitions and alternative outcome variables, analogously to Table 6 for net flows. Table 8 in the Appendix provides additional results on alternative outcomes and specifications. In the majority of cases, the coefficients are estimated with a negative sign and are mostly statistically not significant.

We also explore the influence of fixed effects: our estimation relies on the difference-indifferences between sectors, countries and time. If we do not control for sectoral business cycles $\left(\nu_{s t}\right)$, our results still hold. If we do not control for country-specific business cy-

\footnotetext{
${ }^{35}$ The signs of direct cost and allocation in column (4) are not significant but also identical for source and destination variables. This pattern is surprisingly robust to changes in specification, see Table 8 .
} 
cles $\left(\nu_{m t}\right.$ and $\left.\nu_{x t}\right)$, the conclusions change and even more so, if we do not control for country-pair effects $\left(\nu_{m x s}\right.$ capturing among other factors distance, essential for gravity estimations). ${ }^{36}$ However, we believe that controlling for $\nu_{m t}, \nu_{x t}$ and $\nu_{m x s}$ is essential to identification. Controlling for $\nu_{s t}$ may be optional, and either doing so or not does not change the main results.

Overall, based on our analysis of bilateral trade and emission data, we conclude that the EU ETS did not have a systematic impact on flows of trade or embodied $\mathrm{CO}_{2}$ emissions. Moreover, there is evidence against the hypothesis that $\alpha^{m}=-\alpha^{x}$.

\section{Summary and conclusions}

This paper considers whether the compliance cost imposed by the EU ETS on producers in European manufacturing sectors has caused carbon leakage. Carbon leakage, a special case of the pollution haven phenomenon, is an important topic in the context of unilateral environmental policy. A unilateral policy intervention changes the relative competitiveness of domestic producers vis-à-vis their global competitors. In the extreme case, carbon leakage undoes the contribution of the unilateral policy to mitigate aggregate global emissions, while the region implementing the policy suffers losses in output, employment, and welfare. This loss in competitiveness due to the EU ETS can occur directly, as producers must abate or pay for the cost of their own emissions, and indirectly through the consumption of electricity, when electricity producers pass through emission costs to power prices. In the EU ETS, the direct emission cost was largely defrayed by free allocation during the period under study, such that the majority of sectors enjoy a net subsidy when net direct costs are considered. Moreover, overall emission costs have so far been small compared to other material costs. In addition to low carbon prices and free allocation, there are further obstacles to leakage: relocation is costly and risky, as the new host region may also introduce corresponding policies in the future. Finally, the EU ETS may also have beneficial effects, such as incentivizing green innovation by producers, which help them become more competitive internationally.

Our empirical analysis is based on the hypothesis that leakage can be measured through changes in trade flows, particularly flows in embodied carbon. This hypothesis can be derived from classical trade theory or from New trade theory. Combining data from GTAP, a global trade dataset with input-output information, and administrative data from the EU ETS, we estimate the effect of various potential measures of the stringency of the EU ETS on trade flows in manufactured goods. Our measures of policy stringency account both for the direct emission cost and the indirect emission cost from electricity use. Our empirical analysis follows two traditions in the trade literature: first, we consider the effect of EU ETS stringency on net trade flows, as suggested by the neoclassical trade literature (Ederington et al. 2005), where we also consider sector heterogeneity. In particular, we

\footnotetext{
${ }^{36}$ Results available on request.
} 


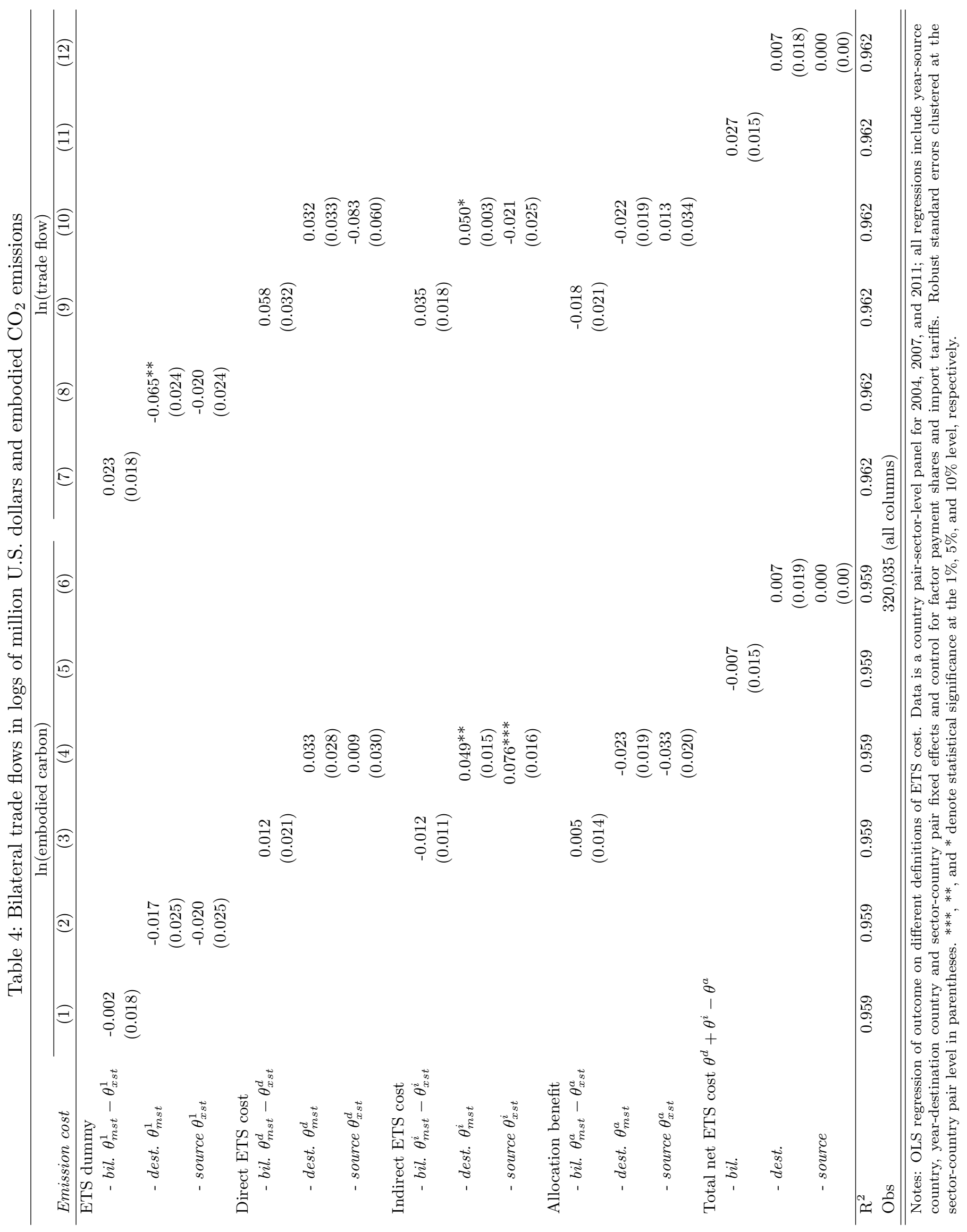


test for a potentially stronger effect of EU ETS stringency on footloose industries and for nonlinearity of the effects of EU ETS stringency. Second, we follow the New trade literature by analyzing the effect of policy stringency on bilateral trade flows (Aichele and Felbermayr 2015).

We find no evidence that the EU ETS has induced carbon leakage in European manufacturing sectors. This result is in line with existing empirical ex post research on carbon leakage due to the EU ETS, but contrasts with predictions from ex ante modeling exercises. Our results relate to existing work on other environmental policies, like Aichele and Felbermayr (2015) who show that ratification of the Kyoto Protocol has caused carbon leakage. Our results suggest that the leakage found by Aichele and Felbermayr (2015) must have occurred in Kyoto signatory countries who were not part of the EU ETS.

The absence of trade effects suggests that the barriers preventing leakage are greater than emission costs inducing leakage. Current allowance prices in the EU ETS are low and firms may have some market power. Tariffs and transportation costs are typically higher than $\mathrm{CO}_{2}$-related costs and contribute to firms' ability to pass-through at least some of their emission cost to the final consumer without losing significant market share. Additionally, more diffuse factors, such as political risk, exchange rate concerns, and considerations about the availability of qualified labor may limit leakage. Further research will help identify factors mainly responsible for the absence of leakage or find a level of the emission cost for which carbon leakage is a real concern.

The absence of carbon leakage is good news for the political feasibility of unilateral $\mathrm{CO}_{2}$ policies such as the EU ETS even in a context of globally asymmetric climate policy, at least at current allowance prices. If they do not hamper domestic competitiveness and economic growth, environmental policies are more likely to be implemented. 


\section{References}

Acemoglu D, Aghion P, Bursztyn L, and Hemous D (2012) The environment and directed technical change. The American Economic Review, 102(1): 131-166.

Aghion P, Dechezleprêtre A, Hemous D, Martin R, and Van Reenen J (2016) Carbon taxes, path dependency, and directed technical change: Evidence from the auto industry. Journal of Political Economy, 124(1): 1-51.

Aguiar A, Narayanan B, and McDougall R (2016) An overview of the GTAP 9 data base. Journal of Global Economic Analysis, 1(1): 181-208.

Aichele R and Felbermayr G (2012) Kyoto and the carbon footprint of nations. Journal of Environmental Economics and Management, 63(3): 336-354.

(2015) Kyoto and carbon leakage: An empirical analysis of the carbon content of bilateral trade. Review of Economics and Statistics, 97(1): 104-115.

Antweiler W, Copeland B. R, and Taylor M. S (2001) Is free trade good for the environment? American Economic Review, 91(4): 877-908.

Branger F, Quirion P, and Chevallier J (2016) Carbon leakage and competitiveness of cement and steel industries under the eu ets: Much ado about nothing. The Energy Journal, 37(3).

Branger F and Quirion P (2014) Climate policy and the 'carbon haven' effect. Wiley Interdisciplinary Reviews: Climate Change, 5(1): 53-71.

Brunel C and Levinson A (2016) Measuring the stringency of environmental regulations. Review of Environmental Economics and Policy, 10(1): 47-67.

Brunnermeier S. B and Levinson A (2004) Examining the evidence on environmental regulations and industry location. The Journal of Environment $\&$ Development, 13(1): $6-41$.

Calel R and Dechezleprêtre A (2016) Environmental policy and directed technological change: Evidence from the European carbon market. Review of Economics and Statistics, 98(1): 173-191.

Carbone J. C and Rivers N (2017) The impacts of unilateral climate policy on competitiveness: Evidence from computable general equilibrium models. Review of Environmental Economics and Policy, 11(1): 24-42.

Caron J, Fally T, and Markusen J. R (2014) International trade puzzles: A solution linking production and preferences. The Quarterly Journal of Economics, 129(3): 1501-1552.

Copeland B. R and Taylor M. S (2004) Trade, growth, and the environment. Journal of Economic literature, 42(1): 7-71. 
(2005) Free trade and global warming: A trade theory view of the Kyoto protocol. Journal of Environmental Economics and Management, 49(2): 205-234.

De Loecker J, Goldberg P. K, Khandelwal A. K, and Pavcnik N (2016) Prices, markups, and trade reform. Econometrica, 84(2): 445-510.

Dechezleprêtre A, Gennaioli C, Martin R, and Muûls M (2014) Searching for carbon leaks in multinational companies. Working Paper 165, Grantham Research Institute on Climate Change and the Environment.

Dechezleprêtre A and Sato M (2017) The impacts of environmental regulations on competitiveness. Review of Environmental Economics and Policy, 11(2): 183-206.

Demailly D and Quirion P (2006) CO2 abatement, competitiveness and leakage in the European cement industry under the EU ETS: Grandfathering versus output-based allocation. Climate Policy, 6(1): 93-113.

Dixit A. K and Stiglitz J. E (1977) Monopolistic competition and optimum product diversity. The American Economic Review, 67(3): 297-308.

Ederington J, Levinson A, and Minier J (2005) Footloose and pollution-free. Review of Economics and Statistics, 87(1): 92-99.

Ellerman A. D, Marcantonini C, and Zaklan A (2016) The European Union emissions trading system: ten years and counting. Review of Environmental Economics and Policy: rev014.

EU (2014) Directive 2003/87/EC of the European Parliament and of the Council of 13 October 2003 Establishing a Scheme for Greenhouse Gas Emission Allowance Trading within the Community and Amending Council Directive 96/61/EC. 2003L0087 - EN $30.04 .2014-00 \% .001-1$.

Fabra N and Reguant M (2014) Pass-through of emissions costs in electricity markets. The American Economic Review, 104(9): 2872-2899.

Gerlagh R and Kuik O (2014) Spill or leak? Carbon leakage with international technology spillovers: A CGE analysis. Energy Economics, 45: 381-388.

Grossman G. M and Krueger A. B (1991) Environmental impacts of a North American free trade agreement. Working Paper 3914, National Bureau of Economic Research.

Harstad B (2012) Buy coal! A case for supply-side environmental policy. Journal of Political Economy, 120(1): 77-115.

Head K and Mayer T (2014) Gravity equations: Workhorse, toolkit, and cookbook. in G. Gopinath, E. Helpman, and K. Rogoff (eds.) Handbook of International Economics, 4: 131-196. 
Hintermann B (2016) Pass-through of CO2 emission costs to hourly electricity prices in Germany. Journal of the Association of Environmental and Resource Economists, 3(4): 857-891.

Huff K, McDougall R, and Walmsley T (2000) Contributing input-output tables to the GTAP data base. Technical Paper 1, Center for Global Trade Analysis, Purdue University.

IPCC (2007) Fourth assessment report (AR4). Synthesis Report, Intergovernmental Panel on Climate Change.

Jaffe A. B, Peterson S. R, Portney P. R, and Stavins R. N (1995) Environmental regulation and the competitiveness of U.S. manufacturing: what does the evidence tell us? Journal of Economic Literature, 33(1): 132-163.

Jensen S, Mohlin K, Pittel K, and Sterner T (2015) An introduction to the green paradox: The unintended consequences of climate policies. Review of Environmental Economics and Policy, 9(2): 246-265.

Koch N and Basse Mama H (2016) European climate policy and industrial relocation: Evidence from German multinational firms. SSRN working paper.

Kronmal R. A (1993) Spurious correlation and the fallacy of the ratio standard revisited. Journal of the Royal Statistical Society. Series A (Statistics in Society), 156(3): 379392.

Krugman P (1980) Scale economies, product differentiation, and the pattern of trade. American Economic Review, 70(5): 950-959.

Kuh E and Meyer J. R (1955) Correlation and regression estimates when the data are ratios. Econometrica, 23(4): 400-416.

Levinson A and Taylor M. S (2008) Unmasking the pollution haven effect. International Economic Review, 49(1): 223-254.

Martin R, Muûls M, de Preux L. B, and Wagner U (2014) Industry compensation under relocation risk: A firm-level analysis of the EU emissions trading scheme. American Economic Review, 104(8): 2482-2508.

Martin R, Muûls M, and Wagner U. J (2016) The impact of the European Union Emissions Trading Scheme on regulated firms: What is the evidence after ten years? Review of Environmental Economics and Policy, 10(1): 129-148.

McGuire M. C (1982) Regulation, factor rewards, and international trade. Journal of public economics, 17(3): 335-354.

Melitz M. J (2003) The impact of trade on intra-industry reallocations and aggregate industry productivity. Econometrica, 71(6): 1695-1725. 
Motta M and Thisse J.-F (1994) Does environmental dumping lead to delocation? European Economic Review, 38(3-4): 563-576.

Pethig R (1976) Pollution, welfare, and environmental policy in the theory of comparative advantage. Journal of Environmental Economics and Management, 2(3): 160-169.

Porter M. E and Van der Linde C (1995) Toward a new conception of the environmentcompetitiveness relationship. The Journal of Economic Perspectives, 9(4): 97-118.

Sartor O (2013) Carbon leakage in the primary aluminium sector: What evidence after 6.5 years of the EU ETS? Working Paper 2012-12, CDC Climat.

Schmidt R. C and Heitzig J (2014) Carbon leakage: Grandfathering as an incentive device to avert firm relocation. Journal of Environmental Economics and Management, 67(2): 209-223.

Schröder C (2016) Industrielle Arbeitskosten im internationalen Vergleich. IW-Trends. Vierteljahresschrift zur empirischen Wirtschaftsforschung, 43(3): 17-26.

Tobey J. A (1990) The effects of domestic environmental policies on patterns of world trade: An empirical test. Kyklos, 43(2): 191-209. 


\section{Appendix}

\section{A. Potential bias from using normalized variables}

The specification of equations (1) and (2) use trade intensity (normalized trade flows) as a dependent variable and environmental policy intensity (normalized emission cost) as main covariate variable. The additional variables transport cost and tariffs are also measured per value unit. We believe this specification represents the relevant magnitudes. Indeed both total emission cost and exports depend on an underlying "sectoral market size" parameter, which would create spurious correlation if not accounted for. Moreover, we compare countries of very different magnitude, where we would face an outlier problem and heteroskedasticity concerns if we were not normalizing. Our normalizations are based on a suggestion of Ederington et al. (2005).

However, the use of ratios is discussed extensively in the statistical literature: when two variables have zero correlation, positive (spurious) correlation might appear in a regression if both left-hand and right-hand side variables are normalized by a common denominator. The bias is even stronger if the variables are correlated with each other and with the common denominator (Kronmal 1993). Note that ratios are generally found to bias the absolute magnitude of estimates upwards (e.g. Kuh and Meyer 1955); as we find no significant impact of policy stringency on trade flows, an upward bias would not change our conclusion and in fact strengthens our results. In this Section, we follow the recommendations of Kronmal (1993) to check that results are not an artifact of normalization.

Let $Y$ be an $n \times 1$ vector, $Z$ a diagonal $n \times n$ matrix and $X$ an $n \times p$ matrix, centered such that the mean of each column is zero (e.g. demeaned). Assume that the true model is:

$$
Y=\mathbb{1}_{n} \beta_{0}+X \beta_{X}+Z \mathbb{1}_{n} v \beta_{Z}+\epsilon
$$

where $\beta_{0}$ and $\beta_{Z}$ are scalars and $\beta_{X}$ a $p \times 1$ vector. $\mathbb{1}_{n}$ is a $n \times 1$ vector of ones. Our main specification can then be written:

$$
Z^{-1} Y=\mathbb{1}_{n} \alpha_{0}+Z^{-1} X \alpha_{X}+\epsilon
$$

Kronmal (1993) shows that estimate $\hat{\alpha}_{X}$ from least squares of equation (4) is in general a biased estimator of $\beta_{X}$. Indeed, dividing both sides of equation (3) by $Z$ yields

$$
Z^{-1} Y=Z^{-1} \mathbb{1}_{n} \beta_{0}+Z^{-1} X \beta_{X}+\mathbb{1}_{n} \beta_{Z}+Z^{-1} \epsilon
$$

The least squares estimates of equation (5) are unbiased estimates of the parameters of equation (3). Empirically, this corresponds to estimating equation (4) and adding the scaling variable as an additional right-hand side variable. Dividing the error term by $Z$ results in heteroskedasticity such that OLS is no longer the efficient estimator.

The result in Table 5 control for the scaling variable, which is total domestic sectoral 
Table 5: Regression of net trade flows on emission cost with additional control for scaling variables (comp. Table 2)

\begin{tabular}{|c|c|c|c|c|c|c|c|c|}
\hline \multirow[b]{2}{*}{ Emission cost } & \multicolumn{4}{|c|}{ Net embodied $\mathrm{CO}_{2} /$ total $\mathrm{CO}_{2}$} & \multicolumn{4}{|c|}{ Net imports/output } \\
\hline & (1) & $(2)$ & $(3)$ & (4) & $(5)$ & (6) & (7) & $(8)$ \\
\hline ETS dummy $\theta_{s t}^{1}$ & $\begin{array}{l}-0.265 \\
(0.351)\end{array}$ & & & & $\begin{array}{c}0.005 \\
(0.053)\end{array}$ & & & \\
\hline Direct ETS $\operatorname{cost} \theta_{s t}^{d}$ & & $\begin{array}{l}-0.258 \\
(0.286)\end{array}$ & $\begin{array}{c}0.733 \\
(0.655)\end{array}$ & & & $\begin{array}{l}-0.007 \\
(0.070)\end{array}$ & $\begin{array}{l}0.311^{*} \\
(0.129)\end{array}$ & \\
\hline Indirect $\mathrm{ETS} \operatorname{cost} \theta_{s t}^{i}$ & & & $\begin{array}{l}-1.837 \\
(1.937)\end{array}$ & & & & $\begin{array}{c}0.027 \\
(0.294)\end{array}$ & \\
\hline Allocation benefit $\theta_{s t}^{a}$ & & & $\begin{array}{l}-0.470 \\
(0.573)\end{array}$ & & & & $\begin{array}{c}-0.252^{*} \\
(0.118)\end{array}$ & \\
\hline Total net ETS $\operatorname{cost} \theta_{s t}^{t o t}$ & & & & $\begin{array}{l}-0.704 \\
(1.151)\end{array}$ & & & & $\begin{array}{c}0.129 \\
(0.162)\end{array}$ \\
\hline Scaling variable & $\begin{array}{c}0.944 \\
(0.73)\end{array}$ & $\begin{array}{l}0.954 \\
(0.73)\end{array}$ & $\begin{array}{l}0.870 \\
(0.69) \\
\end{array}$ & $\begin{array}{l}0.936 \\
(0.73)\end{array}$ & $\begin{array}{l}-722.0 \\
(580.4)\end{array}$ & $\begin{array}{l}-711.1 \\
(562.7)\end{array}$ & $\begin{array}{l}-697.3 \\
(559.5)\end{array}$ & $\begin{array}{l}-693.5 \\
(552.8)\end{array}$ \\
\hline $\mathrm{R}^{2}$ & 0.89 & 0.89 & 0.89 & 0.89 & 0.92 & 0.92 & 0.92 & 0.92 \\
\hline Obs & & & & $3,075($ & olumns) & & & \\
\hline
\end{tabular}

Notes: OLS regression of outcome on different definitions of ETS cost, controlling for scaling variables. Data is a sector-country-level panel for 2004, 2007, and 2011; all regressions include year and sector-country fixed effects and control for factor payment shares, tariffs, and transport costs. Robust standard errors clustered at the sector-partner country level in parentheses. ${ }^{* * *},{ }^{* *}$, and ${ }^{*}$ denote statistical significance at the $1 \%, 5 \%$ and $10 \%$ level, respectively.

product for imports in value and total domestic sectoral emissions for imports in embodied carbon. Including this value is necessary if the true model is given by equation (3) rather than our model as in equation (4). Table 5 shows that our results are robust to this modification, as magnitudes and significance remain virtually unchanged

For bilateral data, our main specifications in Table 4 use logarithms rather than normalizing the variables, following Aichele and Felbermayr (2015). The regressions using raw (not normalized or in logs) variables suggest a significant correlation of surprising sign; however, this effect vanishes when using normalized variables or logs. We again test if the normalization for bilateral data is problematic and find that the coefficients change little when including the scaling variable. ${ }^{37}$

\footnotetext{
${ }^{37}$ Results available on request.
} 


\section{B. Additional regression results}

\section{B.1. Net trade flows}

Table 6: Summary overview stating only the coefficient of the ETS stringency variables (for different specifications of net flows)

\begin{tabular}{|c|c|c|c|c|c|}
\hline Outcomes & $\begin{array}{l}\text { ETS } \\
\text { dummy } \\
(1)\end{array}$ & $\begin{array}{l}\text { Total ETS } \\
\text { cost } \\
(2)\end{array}$ & $\begin{array}{l}\text { Direct ETS } \\
\text { cost } \\
(3 \mathrm{a})\end{array}$ & $\begin{array}{l}\text { Indirect } \\
\text { ETS cost } \\
(3 \mathrm{~b})\end{array}$ & $\begin{array}{l}\text { Allocation } \\
(3 \mathrm{c})\end{array}$ \\
\hline Net carbon imports (MtCO2) & $\begin{array}{l}0.012 \\
(0.083)\end{array}$ & $\begin{array}{l}0.022 \\
(0.144)\end{array}$ & $\begin{array}{l}1.102 \\
(1.047)\end{array}$ & $\begin{array}{l}-0.145 \\
(0.440)\end{array}$ & $\begin{array}{l}-0.796 \\
(0.743)\end{array}$ \\
\hline Net imports (Mil. US $\$$ ) & $\begin{array}{l}180.0 \\
(175.7)\end{array}$ & $\begin{array}{l}267.5 \\
(196.8)\end{array}$ & $\begin{array}{l}686.8 \\
(600.2)\end{array}$ & $\begin{array}{l}745.0 \\
(762.7)\end{array}$ & $\begin{array}{l}-453.1 \\
(381.3)\end{array}$ \\
\hline Net carbon/total carbon $(\%)$ & $\begin{array}{l}-0.273 \\
(0.354)\end{array}$ & $\begin{array}{l}0.684 \\
(0.552)\end{array}$ & $\begin{array}{l}0.782 \\
(0.657)\end{array}$ & $\begin{array}{l}-1.987 \\
(1.983)\end{array}$ & $\begin{array}{l}-0.495 \\
(0.576)\end{array}$ \\
\hline -w/o factor payment & $\begin{array}{l}-0.147 \\
(0.242)\end{array}$ & $\begin{array}{l}-0.257 \\
(0.274)\end{array}$ & $\begin{array}{l}0.957 \\
(0.768)\end{array}$ & $\begin{array}{l}-1.902 \\
(1.638)\end{array}$ & $\begin{array}{l}-0.494 \\
(0.482)\end{array}$ \\
\hline Net imports/output value (\%) & $\begin{array}{l}0.001 \\
(0.052)\end{array}$ & $\begin{array}{l}0.174 \\
(0.142)\end{array}$ & $\begin{array}{l}0.310^{*} \\
(0.129)\end{array}$ & $\begin{array}{l}0.033 \\
(0.295)\end{array}$ & $\begin{array}{c}-0.256^{*} \\
(0.117)\end{array}$ \\
\hline -w/o factor payment & $\begin{array}{l}0.001 \\
(0.043)\end{array}$ & $\begin{array}{l}0.017 \\
(0.061)\end{array}$ & $\begin{array}{l}0.221 \\
(0.119)\end{array}$ & $\begin{array}{l}-0.081 \\
(0.292)\end{array}$ & $\begin{array}{l}-0.133 \\
(0.101)\end{array}$ \\
\hline
\end{tabular}

Notes: Summary table of regressions of different outcome variables (rows) on different ETS stringency variables (columns). In column 1 and 2 , each coefficient comes from a separate regression. In columns $3 \mathrm{a}$ to $3 \mathrm{c}$, each row is a regression of the outcome on direct cost, indirect cost and allocation. All regressions include fixed effects and controls mentioned in our main results. Robust standard errors clustered at the sector level in parentheses. $* * *, * *$, and $*$ denote statistical significance at the $1 \%, 5 \%$ and $10 \%$ level, respectively. 


\section{B.2. Bilateral trade flows}

Table 7: Summary overview stating only the coefficient of the bilateral ETS stringency variables (for different specifications of bilateral flows)

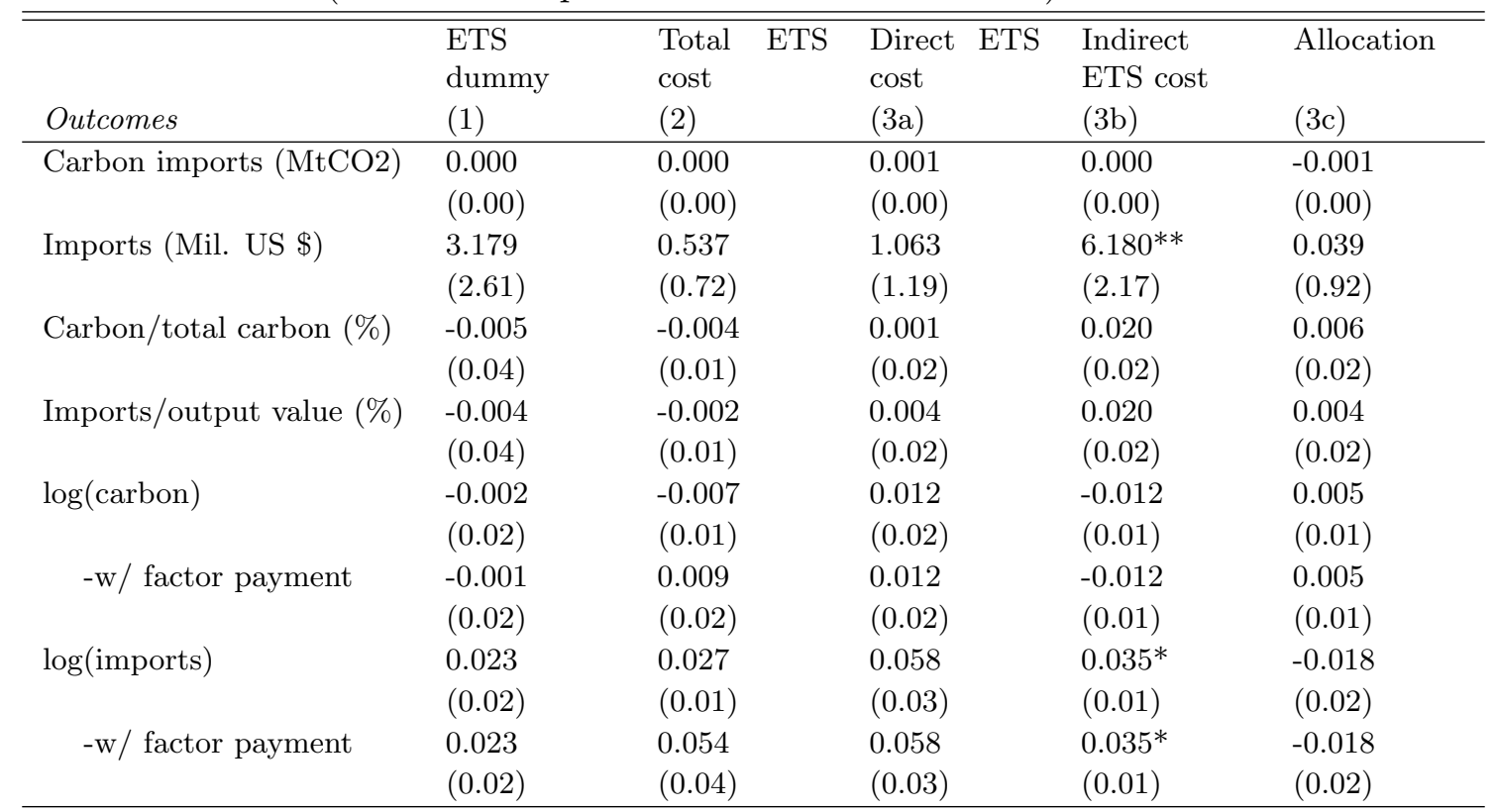

Note: Summary table of regressions of different outcome variables (rows) on different ETS stringency variables (columns); bilateral treatment indicator is defined as treatment for the destination country minus treatment for the source country. In column 1 and 2, each coefficient comes from a separate regression. In columns 3a to 3c, each row is a regression of the outcome on direct cost, indirect cost and allocation. All regressions include yearsector and sector-country-pair fixed effects, as mentioned in our main results. Robust standard errors clustered at the sector level in parentheses. ***, **, and * denote statistical significance at the $1 \%, 5 \%$, and $10 \%$ level, respectively. 


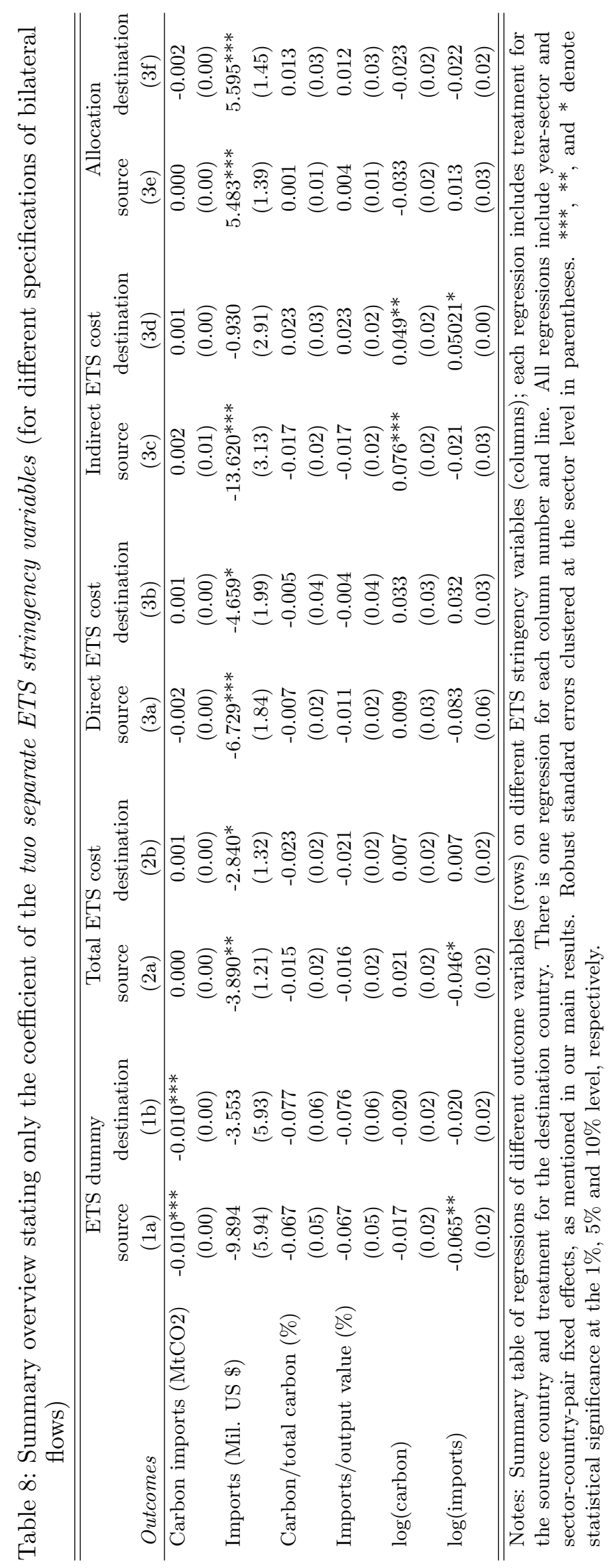

